\title{
Metric Ambiguity and Flow in Rap Music: A Corpus-Assisted Study of Outkast's “Mainstream” (1996)
}

\author{
MITCHELL OHRINER[1] \\ University of Denver
}

\begin{abstract}
Recent years have seen the rise of musical corpus studies, primarily detailing harmonic tendencies of tonal music. This article extends this scholarship by addressing a new genre (rap music) and a new parameter of focus (rhythm). More specifically, I use corpus methods to investigate the relation between metric ambivalence in the instrumental parts of a rap track (i.e., the beat) and an emcee's rap delivery (i.e., the flow). Unlike virtually every other rap track, the instrumental tracks of Outkast's "Mainstream” (1996) simultaneously afford hearing both a four-beat and a three-beat metric cycle. Because three-beat durations between rhymes, phrase endings, and reiterated rhythmic patterns are rare in rap music, an abundance of them within a verse of "Mainstream" suggests that an emcee highlights the three-beat cycle, especially if that emcee is not prone to such durations more generally. Through the construction of three corpora, one representative of the genre as a whole, and two that are artist specific, I show how the emcee T-Mo Goodie's expressive practice highlights the rare three-beat affordances of the track.
\end{abstract}

Submitted 2015 July 15; accepted 2015 December 15.

KEYWORDS: corpus studies, rap music, flow, T-Mo Goodie, Outkast

THIS article uses methods of corpus studies to address questions of creative practice in rap music, specifically how the material of the rapping voice - what emcees, hip-hop heads, and scholars call "the flow"-relates to the material of the previously recorded instrumental tracks collectively known as the beat. As Paul Edwards (2009) documents in his extensive interviews with emcees, a host of relationships between the flow and the beat are possible. Some emcees come to the beat with pre-composed lyrics, ranging in length from phrases to entire verses, and coerce the rhythms of those words to the meter of the beat. Consider the practice of MC Serch of $3^{\text {rd }}$ Bass as an example:

I write a rhythm and a flow, and then I wait for the right beat that matches that rhythm and flow. Very rarely [do I write to the beat (p. 171)].

Other emcees want their flows to align with the material of the beat. As Nelly relates,

I like to listen to the beat, get a nice groove for it, and see where the beat takes you. It's impossible to do the same style on every beat, I feel (p. 169).

Still others begin writing by improvising through "scat singing," finding an appealing rhythmic pattern and subsequently searching for words with suitable rhythms (p. 114).[2]

An emcee like MC Serch, writing verses without first hearing the beat, is confident that an appropriate beat will emerge because of the invariants of metric structure in rap music. Rap beats typically consist of bass-drum events on beats one and three alternating with snare-drum events on beats two and four, a configuration known as the "boom-bap."[3] Several other instrumental streams variegate the beats of different tracks, but virtually all rap songs share this four-to-a-bar metric structure wrought primarily by the percussion.[4] Because that structure is invariant, it can be difficult to determine whether an emcee has crafted a verse with a particular beat in mind, rather than the general metric features of the genre.

The metric structure of Outkast's "Mainstream," from their second album, ATLiens, differs from the vast majority of other rap tracks and provides an opportunity to examine the relationship between a particular flow and a particular beat. As I will describe below, "Mainstream" proffers two metric structures to an emcee, the typical duple meter (i.e., 4/4) as well as a triple meter (i.e., 3/4). In this article, I will argue 
that different emcees on the track attend to different aspects of the metric structure; I will support this argument through the construction of a corpus of rap flows representative of the genre as a whole and two separate corpora of individual emcees' flows. The corpus analysis will highlight unusual features of one of the verses of the track, features that cannot be explained by conventional modes of emceeing nor by the style of the artist of the verse. Instead, I will assert that at least some aspects of one of the verses have been tailored to the particularities of the beat of "Mainstream."

My proximal motivation in undertaking this study is to examine the relationship between the flow and the beat of a particularly interesting song, an interest shared by Yasin (1997), Wood (1999), Miyakawa (2005), Adams (2009), Woods (2009), Caldwell (2010), and Kautny (2015). I also wish to address what I consider to be two gaps in the quickly growing collection of musical corpus studies. A generation ago, when music theorists first began publishing studies of popular music, scholars from other disciplines, especially musicology and sociology, took issue with music theory's primary focus on structures of melody and harmony (McClary \& Walser, 1990; Shepherd, 1991; Covach, 1999). Contemporary repertoires supposedly focus on rhythm, timbre, and the embodied feel of playing instruments like the guitar to a greater extent than Western classical music (Shepherd, 1982, p. 52). By ignoring these aspects of the music and importing methods of analysis designed for older genres, music theorists allegedly both missed the point of the music and furthered colonialist agendas (Middleton, 1990, p. 105; Frith, 1987, p. 145).

Even at that time music theory was not as myopic as its detractors maintained, and the last two decades have seen a flowering of analytical methods that address all parameters of popular music.[5] Yet the emerging literature of music corpus studies primarily focuses on questions of pitch, melody, and harmony (e.g., DeClerq \& Temperley, 2011; Temperley, 2011; Burgoyne, Wild, \& Fujinaga, 2013; Quinn $\&$ White, 2015). Because scholars in music information retrieval have addressed the digital representation of pitch, both as low-level audio features and symbolic chord structures (e.g., Müller, 2007; Selfridge-Field, 1997), it is unsurprising that the first corpus analyses of popular music would start by addressing those features. By presenting representations of aspects of flow, I hope to broaden the parameters of interest to computational music analysts, not only towards rap music and hip-hop, but also to other genres predicated on rhythmic vocal expression.

A second gap I wish to address here is the paucity of corpus studies aimed at contextualizing individual expressive decisions. In his landmark study on modes of analysis, Leonard B. Meyer (1973) distinguishes between what he calls style analysis and critical analysis. Style analysis explicates the "rules of the game" operating in particular genres, features of the genre that artists are more or less obligated to replicate in each new piece. Critical analysis examines and interprets the choices composers make at each moment of an individual piece. These two modes of analysis are symbiotic: analysts build an overarching description of a style incrementally through successive critical analyses of pieces in that style. At the same time, refinements to one's sense of the operative procedures of a style recast interpretations in critical analyses. Because corpus studies have at their disposal large collections of pieces, it is natural that style analyses would dominate initially. This is what studies of corpora do best-describe features of styles (e.g., tendencies of harmonic progressions) in a way that can be verified without recourse to the authority of the analyst. But corpus studies can also aid critical analysis by contextualizing the options artists face at each point of composition. By showing how the construction of corpora can corroborate the assertions of a critical analysis of a flow, I also hope to persuade music theorists that the corpus-study method, while a new technique, supports the work they are already doing.

In the remainder of this article, I will first detail the unique metrical ambiguity of "Mainstream.” I will then describe the construction of a corpus of rap flows and detail the ways in which flow supports the four-to-a-bar meter of the typical rap beat through features of rhythm, rhyme, phrasing, and accent. I will then examine the first two verses of "Mainstream," looking for traces of the triple-meter aspects of the beat. T-Mo Goodie of the Goodie Mob and André 3000 of Outkast perform these verses. These two rap groups epitomize southern rap of the 1990s, centered in Atlanta; indeed, they are among the earliest commercially successful rappers from neither the East Coast nor the West Coast (Sarig, 2007). T-Mo's verse has features that align with the triple-meter affordances of the beat in a way that is unexpected both in the broader, representative corpus of rap music and in a smaller corpus of other T-Mo verses. This correspondence suggests a different way of listening to the verse, and I will close by detailing some of the consequences of that perspective. 


\section{METRIC AMBIGUITY IN THE “MAINSTREAM” BEAT}

The metric ambiguity of "Mainstream" is almost wholly absent in rap music generally. Rap music arose in the late 1970s and early 1980s as dance music, and much of the genre maintains a connection to bodily movement, whether to the b-boy on the dance floor or the hip-hop head bobbing her head in the car (Johnson, 2015). An unrelenting duple meter facilitates this movement. In contrast to other rap beats, the three instrumental streams that comprise the beat produced by Organized Noise offer conflicting metric organizations. The drums, the usual boom-bap with high hat hits at every eighth note, are clearly duple. The speech sample, ya'll know what it is, is less clearly duple. Borrowed from an earlier Goodie Mob song ("Sesame Street," from Soul Food, 1995), the sample recurs every twelve beats. As an even number of beats, this duration is duple at lower levels of metric structure. But at a higher level, the level of groups of measures, it posits three-measure groups rather than the four-measure hypermeasures typical of the genre. The metric ambiguity of the beat arises more clearly through the electric guitar played by Terry Martin. Fig. 1 transcribes the guitar part comparatively in $4 / 4$ and in 3/4. The 3/4 transcription places long notes and chord changes on the downbeat. Were it heard alone, it would undoubtedly be understood as triple meter material. Heard in the $4 / 4$ context generated by the drums, it disperses its most prominent events throughout the measure.
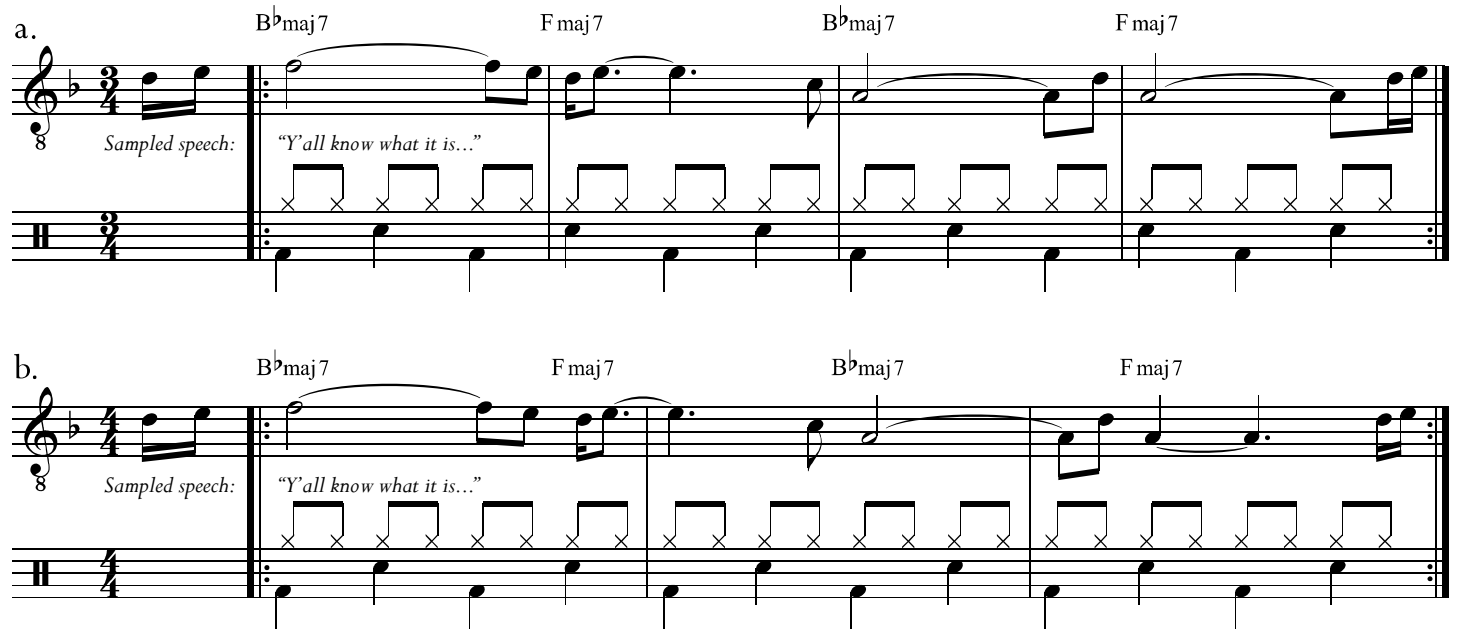

Fig. 1. Terry Martin's guitar line for the beat of Outkast's “Mainstream," transcribed in a triple meter (a) and a duple meter (b).

The entrance of the guitar part furthers the metric ambiguity of the beginning of the song, transcribed in Fig. 2. The opening offers few metric cues, and many of those it does offer conflict. The first long note (D5) lasts two beats, a duple duration that is replicated between the paralleled triplet-sixteen gestures landing on A4 and D5. The following C5/F5 fourth lasts four beats, another duple duration, but begins on a weak beat with reference to what has already been heard. Towards the end of the opening, a three-beat duration emerges through the eighth-note descent from C6, conflicting with the duple suggestions of the previous material and the genre as a whole. The response this material elicits is likely metric confusion. However, if one were to count in threes from the first F5, the first beat of the introduction would be heard as a downbeat. If one starts counting in fours, the song proper must begin with a metric readjustment.

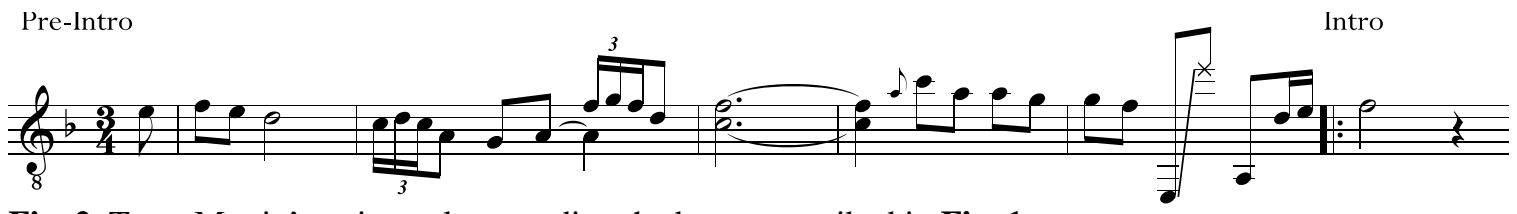

Fig. 2. Terry Martin’s guitar solo preceding the beat transcribed in Fig. 1. 
In addition to the guitar component of the beat, the hook of the song, repeated between each verse, also suggests a triple meter. Fig. 3 transcribes, in both $3 / 4$ and 4/4, the part of the hook rapped collectively by all the emcees involved in the song. Because it is 12 beats long, one could hear either a duple or a triple meter. But listeners familiar with hip-hop music might prefer the 3/4 hearing for several reasons. In 3/4, the hook is four measures and not three, and those measures have a greater sense of internal repetition. Pairs of measures (1 paired with 3 and 2 paired with 4) begin their lyrics in the same part of the measure, have similar syllable counts, and rhyme in similar metric positions.

a.

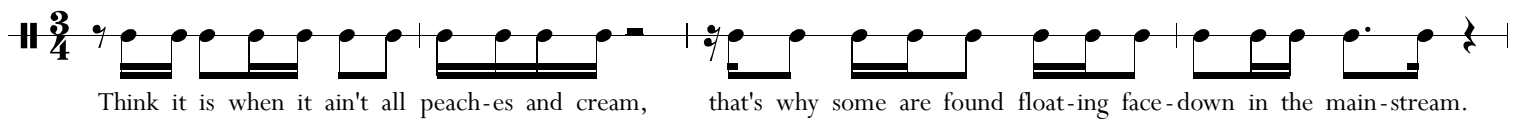

b.

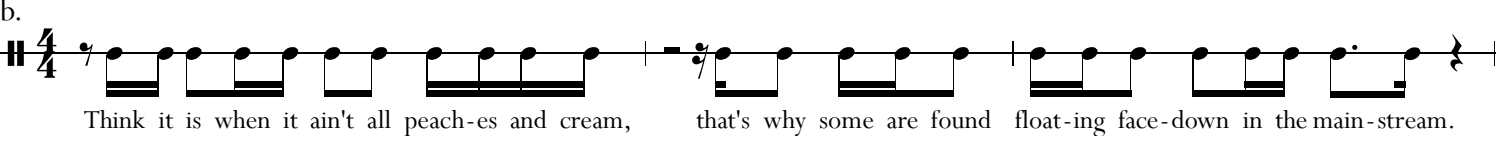

Fig. 3. The collective rapping of the hook of "Mainstream," heard between each verse.

This metric ambiguity is not lost on the emcees who rap on "Mainstream.” In a recent interview, primarily about the experience of producing a track for Aretha Franklin, Ali Shaheed Muhammad (ASM) of A Tribe Called Quest asked André 3000 (A3K) about "Mainstream" and elicited the following exchange:

ASM: It’s funny, one of my favorite songs is 'Mainstream,' like...

A3K: Yeah, yeah...

ASM:...I don't what it is about that song, everything is just so colorful and just, the feeling, it just takes you on a journey.

A3K: That's one of my favorites as well, man, the way it was put together. Organized Noise, that was one of their shining moments, you know, when it came to the production, even just that time signature which, you know, was everything to me.

ASM: How do you deal with, um...do you consciously focus on going outside of, like, regular $4 / 4$ ? You just seem really just open and just going with it. I'm just curious as to, like, the method.

A3K: I'm open as a producer. I didn't start producing until the second album. Our entire first album was produced by Organized Noise. But me personally as a producer, I'm just looking for the next thing that's gonna excite me. So it doesn't have be a certain thing. It has to always be moving forward just for myself. It doesn't have to be new to you it just has to be new to me...Time signatures, I love when I hear different time signatures. It's funny: I had to tell Aretha Franklin that she...the song "Say a Little Prayer" had a lot to do with the song "Hey Ya." They're similar: it's hard to explain, but listening to that song, the way the loop comes back around is kinda how I devised "Hey Ya." And I had to tell her that, that she was a big part of that song (Muhammad \& Kelley, 2014).

While André 3000 doesn't explicitly discuss the metric ambiguity of "Mainstream," his reference to "Hey Ya" is telling. "The way the loop comes back around" refers to a shortened measure in the middle of each phrase of the verses, a feature "Hey Ya" shares with the "Say a Little Prayer." Music theorists might distinguish these two tracks according to Krebs's (1999) terminology of grouping dissonance ("Mainstream") versus displacement dissonance ("Hey Ya"). While the two songs have different kinds of metric disturbances, I suspect André 3000 associates them because of their metric particularities. It is unclear whether the other emcees on the track are aware of the metric ambiguity, and I have been unable to 
ask them myself, but I believe, in light of André 3000's comment, that each emcee understood the metric ambiguity to be a feature of the beat.

The four emcees of "Mainstream" therefore have a decision to make: should the metric ambiguity affect their flow? And if it does have an impact, what would the trace of that impact be in the material of the flow? Through a critical analysis of a verse, we can suggest that certain features are consistent with the triple-meter aspects of the beat. But corpus studies can further support that argument by demonstrating that those features are emblematic of neither the genre as a whole nor the output of the artist emceeing the verse. This comparison of features across different scales - the verse, the artist's output, and the genre- underlies the argument that T-Mo Goodie responds, at least in part, to the triple-meter features of the beat and that, in contrast, André 3000's verse is overwhelmingly duple.

\section{REPRESENTING FEATURES OF FLOW IN CORPORA}

Because rap music invariantly proffers a duple meter, we can assume that rappers typically support that meter through the material of their flows. Detailing how this support works requires constructing a corpus of rap verses and digitally encoding their material. Any inferences we make about emceeing with reference to the corpus depend on the quality of its construction. Although corpus studies are a relatively recent development in music scholarship, linguistics has employed corpus techniques for decades. Corpus scholarship in linguistics has long distinguished between corpora of populations and corpora of samples. A population corpus contains every document that matches certain criteria, for example, every text of written English published in a particular year. If encoding the corpus is costly, one could cull the population through random sampling and encode only a small portion of the population. This random sampling could be structured so that one encoded a representative sample of a number of subpopulations. For example, if $20 \%$ of the population consisted of books and $20 \%$ consisted of newspapers, one might sample randomly in a way that maintains those proportions (Biber, 1990).

Because of developments in optical character recognition (OCR), contemporary corpuses for linguistic study consist of very large populations of millions of texts and hundreds of millions of words (e.g., Ide \& Macleod, 2001; Davies, 2008). A corpus of rap verses cannot at present draw on automatic methods of transcription analogous to OCR and therefore such a corpus must strive to be a representative sample of verses, however small.[6] DeClerq and Temperley (2011) faced a similar issue in constructing a corpus of harmony in rock music. They chose to encode a sample of 500 songs identified as "the best songs" by editors of Rolling Stone magazine. In my view, a representative sample should not necessarily aim for "the best performances," but rather a broad spectrum of the genre. Therefore, I sample from six sources that identify exemplary emcees but construe the definition of "exemplary" differently. These sources, listed in Fig. 4, variously prioritize commercial success, critical acclaim, influence, novelty, and obscurity. They identify 225 artists and groups, some of whom appear on multiples lists. From those, I sample 75 artists that maintain the chronological and geographic distribution of the whole.[7] Having selected the artists for the corpus, I then select one verse for each and encode features of the flow of that verse. I use the now defunct Echo Nest API to select a song for each artist; I then select the longest verse of that song. I do this through Echo Nest's "hotttnesss" feature (Lamere, 2009), a proprietary measure of the prominence of a song through mentions in social media. In order to make a more detailed study of two of the verses of "Mainstream," I also constructed smaller corpora of ten verses each by the emcee T-Mo Goodie and André 3000. A list of songs included in these corpora is given in Appendix 4.

1. The Source Magazine, “Top 50 Lyrical Leaders” (various authors 2012)

2. Complex Magazine, "Best Selling Albums of All Time” (Ross 2013)

3. B.E.T., "The Fifty Most Influential Rappers” (Gale 2011)

4. Complex Magazine, "Fifty Most Slept-On Rappers of All Time” (Drake et. Al 2012)

5. XXL, "Freshman Class," 2008-2014

6. [All albums receiving a score higher than 85 (out of 100) on metacritic.com].

Fig. 4. Six lists of "great" emcees, each with a differing construal of value. 
There are many features of flow that we might choose to represent in the corpus, and the selection of features will limit the kinds of analyses that can be undertaken. For the purposes of this article, I will represent each syllable's onset, position in its phrase, status as accented or unaccented, and participation in rhyme patterning. To represent rhythm, I record each syllable's duration in "musical time" with two integers, the first indicating the number of such durations that would comprise a complete measure and the second indicating how many of those durations comprise the duration of the syllable. For example, a "dotted eighth note" is represented as $(16,3)$ or "three sixteenth notes." A quarter note is represented as $(4,1)$. I also indicate the measure and beat of the first syllable, indexing each from zero. (Any "pick-up" occurs in m. -1). Therefore, the metric position of the onset of a syllable-its "beat index"-is the sum of all previous syllables' durations and metric position of the first syllable. Dividing this beat index by 4 and discarding the remainder gives the measure of a syllable. The beat index modulo 4 gives the beat of the syllable.

I also note which syllables form the ends of segments of rapping. This can sometimes be an easy decision. Fig. 5 shows four measures of Bubba Sparxxx's "Deliverance," which constitutes some of the simplest rapping I know. The figure introduces my method of transcription. Each line is a measure of rapping. The tallest hashes divide the line into four beats; smaller hashes divide the beats into four parts (corresponding to sixteenth notes). Each measure of "Deliverance" contains a segment of rapping, and three different criteria-rhyme, breathing, and syntactical closure-all support this segmentation. In the plot, therefore, I place a comma on beat four of each measure to indicate the segmentation. In many cases, however, these criteria would suggest differing segmentations. Analysts will differ on the weight they give one criterion or another. An analyst with an orientation towards lyric poetry might try to segment a verse into "lines" of lyrics. Here, "line" is usually a metaphor as the lyrics are rarely transcribed by the artist. Bradley and DuBois (2010), for example, advocate segmenting lyrics into lines to highlight poetic devices like enjambment and internal rhyme. One with an orientation towards music analysis might choose to segment according to where the emcee breathes. Usually but not always, breaths coincide with syntactical closure and the musical connotations of "phrasing." I use both these criteria to determine two segmentations of a verse, into both lines and phrases. All the syllables said in one breath comprise a phrase of rapping. A line of rapping is a segmentation such that there are as many segments as there are measures in the verse and each segment is relatively closed syntactically.
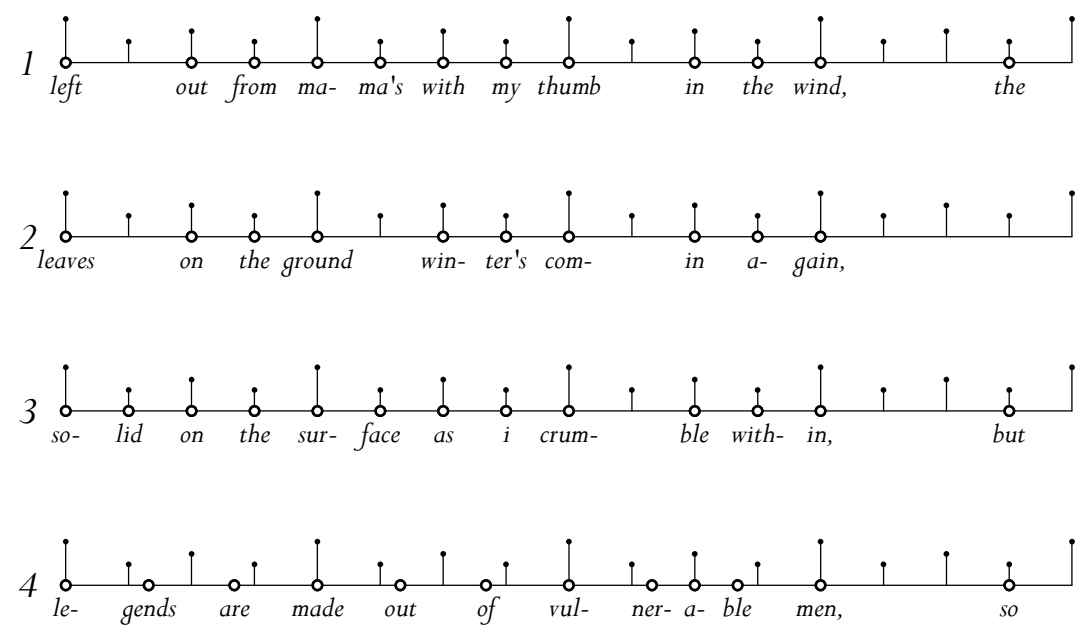

Fig. 5. Bubba Sparxxx, “Deliverance,” mm. 1-4 (Douglas, 2003).

I also encode the rhyme scheme of the verse. Rhyme is a patterning of sounds in which syllables share a correspondence among their vowel and terminal consonant(s). But the perception of rhyme will vary among listeners based on a variety of factors (Brogan, 1993). The duration between two (sets of) syllables may be too large or too small to be heard as a rhyme. Fig. 6 transcribes the lyrics of the first 
quatrain of a verse from The Roots's "Game Theory" performed by the emcee Black Thought (Thompson et. al, 2006). Start it at, part a' that, heart attack, start a' crack, and Almanac all rhyme; I will call these phrases together a "rhyme class." The two syllables of downtown also rhyme, though I doubt listeners would ascribe the same experience of rhyme between those successive syllables and the patterning of the ends of lines. Thus there would seem to be a lower limit for durations that allow for rhyme between similar syllables. I would assert that there is an upper limit as well. Say two pairs of lines exhibit end rhymes that employ the same sounding syllables, but these pairs are a dozen measures apart and many other different end rhymes intervene.[9] While listeners will hear the later paired couplet as a rhyme, I doubt they will relate it to the earlier couplet.

Where I'mma start it at? See I'm a part a' that

Downtown Philly where it's realer than a heart attack.

It wasn't really that ill until the start a' crack.

Now there's a body caught ev'ry night on the Almanac.

Fig. 6. The Roots, “Game Theory,” lyrics of mm. 1-4.

Because rhyme so permeates rap lyrics, emcees construe "similarity" between vowels and terminal consonants quite liberally. So-called "slant rhyme" abounds in rap music, so often in fact that a theory of rhyme developed from rap lyrics instead of lyric poetry would probably not distinguish "exact rhyme" and "slant rhyme." But there is a spectrum of tolerance for difference in sound, and thus not all listeners will hear rhymes with minimal phonetic similarity as rhymes. All these reasons make the automatic labeling of rhyme difficult.[10] I therefore label rhyme manually, and I suspect my annotation of rhyme is especially permissive of phonetic similarity and longer inter-rhyme durations. I annotate rhymes, like durations of syllables, with a pair of integers. The first indicates the ordinal number of the rhyme class in a verse; the first rhyme class (e.g., start it at, part a' that, etc.) is 1, the second is 2, etc. The second integer indicates the ordinal position of the syllable within the rhyme class. Thus at in start it at is represented as $(1,3)$.

Finally, I encode the accent structure of the lyrics. Accent is a particularly thorny concept in analyzing flow. Music theory and phonology have each independently developed theories of accent for music and speech, respectively; Patel (2008) gives an excellent overview of the differing approaches of these two disciplines. Flowing to a beat is some amalgamation of speech and music. On the one hand, the words an emcee raps have an accent structure familiar to listeners from their use in connected speech (e.g., attáck, Phílly, etc.). On the other hand, these words are set to a rhythm that has its own accent structure that may conflict with the one posited by phonetic features. Perhaps some set of phonetic features—pitch height, vowel length, loudness, etc.-influences accent (Ladefoged \& Johnson, 2011), but these features do not map to accent in any deterministic way. As Hayes puts it, "because the relation between stress and pitch/duration is both indirect and language-specific, it is impossible to 'read off' stress contours from the phonetic record (1995, p. 8).” In any event, this “phonetic record” cannot be isolated in the mixed audio of rap music.

My method of labeling accent results from my attempt to design an algorithm that reproduces my own intuitive annotations of accent in rap lyrics. Future transcriptions will place larger circles above the texts of accented syllables. The specific implementation of the algorithm in the R programming language is given in Appendix 1. In general, the algorithm operates on the following principles:

1. Syllabic stresses of multi-syllable words are more likely accents than the syllabic nonstresses of those words.[11]

2. Syllables on the beat are more likely accents than syllables not on the beat.

3. Syllables longer than a sixteenth note are more likely accents than syllables a sixteenth note or shorter.

4. There cannot be consecutive accents a sixteenth note or less apart.[12] 


\section{FLOW AND DUPLE METER IN THE GENRE-WIDE CORPUS}

These four features-rhythm, segmentation, rhyme, and accent—enable us to examine how flow typically supports the duple meter of rap music. Fig. 7 shows the density function of phrase endings and line endings within the measure for the roughly 5000 phrases and lines in the genre-wide corpus.[13] Most lines end near the fourth beat. There are more phrases than lines, and most phrases end near the fourth beat, though a significant number also end towards the beginning of the measure. Fig. 8 recasts Fig. 7 by plotting density functions of phrase and line endings assuming a three-beat measure instead of a four-beat measure. The structure of Fig. 7 evaporates in Fig. 8, suggesting that three beats are not a meaningful duration in how emcees construct their verses.

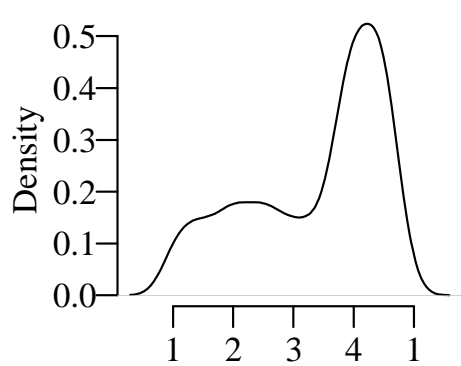

beat of phrase endings

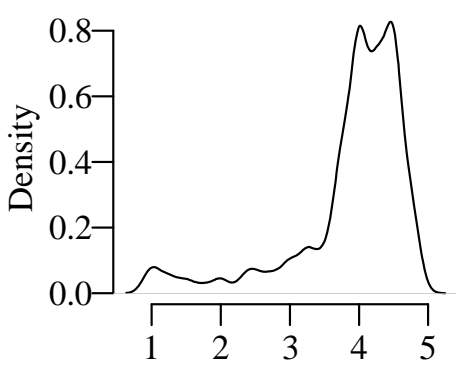

beat of line endings

Fig. 7. Density function of phrase endings (left) and line endings (right) within the measure in the genrewide corpus.
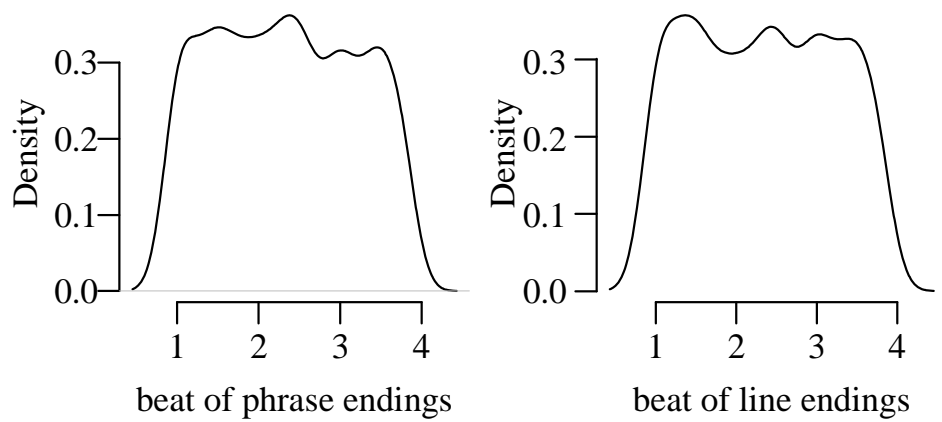

Fig. 8. Density functions of phrase endings and line endings assuming three-beat measure in the genre-wide corpus.

Emcees' flows also support rap's duple meter through a concept I call rhyme projection, a measure of how frequently the sound of a rhyme will be repeated after a certain duration. Rhyme projection is not as simple as the durations between instances within a rhyme class because some of those instances can be understood as "internal rhymes." Suppose the "Game Theory" quatrain in Fig. 6 was slightly changed, with harbor that replacing Philly where, i.e.:

Where I'mma start it at? See I'm a part a' that

Downtown harbor that is realer than a heart attack.

It wasn't really that ill until the start a' crack.

Now there's a body caught ev'ry night on the Almanac.

All the inter-rhyme durations of the class of start it at, part a' that, harbor that and heart attack would be two beats in Black Thought's delivery. Attending to these durations would obscure the significance of the four-beat durations between part a' that and heart attack.

The concept of rhyme projection, therefore, begins by taking the subset of beat indexes that carry the last accented syllable of a rhyme instance and measures all the durations among these indexes, discarding those that are more than six beats.[14] I then round the durations and tabulate the results, 
dividing by the total number of inter-rhyme intervals to yield the proportion of intervals that corresponds to any particular duration.[15] A verse like Bubba Sparxxx's "Deliverance," comprised entirely of beat-four end rhymes, will have a projection vector in which 4-beat rhymes approach $100 \%$ and all other durations are zero. Fig. 9 plots the projection vector of the seventy-five verses of the corpus as a bar graph. Not surprisingly, four-beat and two-beat rhymes predominate. Together, they are seven times as frequent as three-beat rhymes.

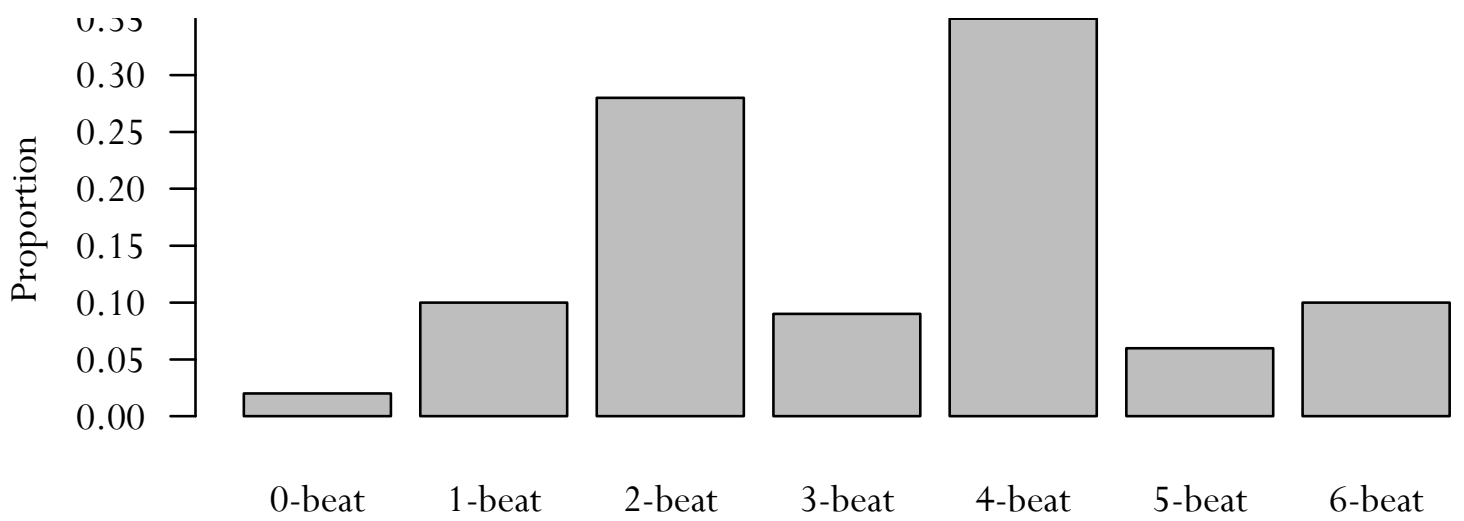

Fig. 9. Durations between beats that carry the last accent of a rhyme instance. Other rhyme instances may intervene.

Rhythmic patterning is the third means by which emcees support rap's duple meter. Many approaches in identifying rhythmic patterning are possible, but the one I'll pursue here is the patterning of relationships between accents and beats. Fig. 10 shows a transcription of the first four measures of Jay Rock's "Pay For It." Seven times in these measures Jay Rock places accents on the beat as well as on the last sixteenth-note position of that beat (i.e., load I stroll, road no jac-, cold becom-, soul stand toe, foes these wolves, clothes no weap-, and prosper nig-). These instances of rhythmic patterning do not coincide with the patterning of segmentation or rhyme.
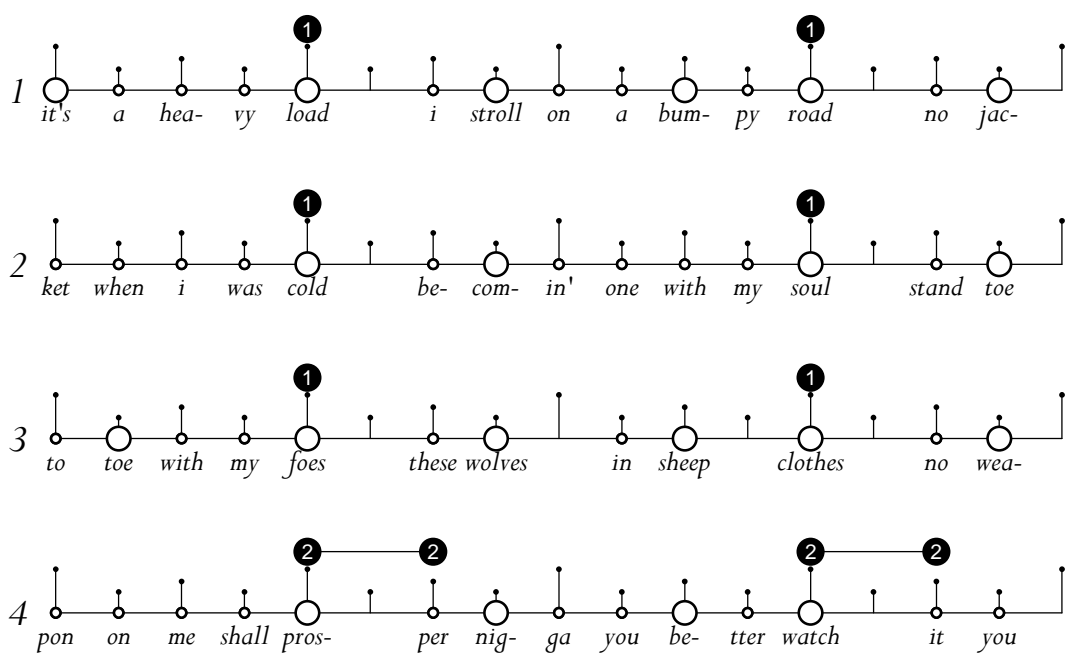

Fig. 10. Jay Rock featuring Chantal and Kendrick Lamar, “Pay For It,” mm. 1-4 (McKinzie 2014).

This particular rhythmic configuration, alternating accents on the beat with those just before the next beat, is especially common among emcees whose beats harken to jazz, soul, and R\&B music. Furthermore, in the Jay Rock example, the durations between beats that share the rhythmic pattern are completely duple. I extend this analysis over the entire corpus, finding all the beats that have accents at 
their beginnings and final sixteenth position. I then create a projection vector of this rhythmic pattern similar to the rhyme projection vector. Fig. 11 shows a bar plot of the projection vector of the durations between beats that share the rhythmic pattern. As with the rhyme projection vector, the rhythmic patterning overwhelming supports duple organization.

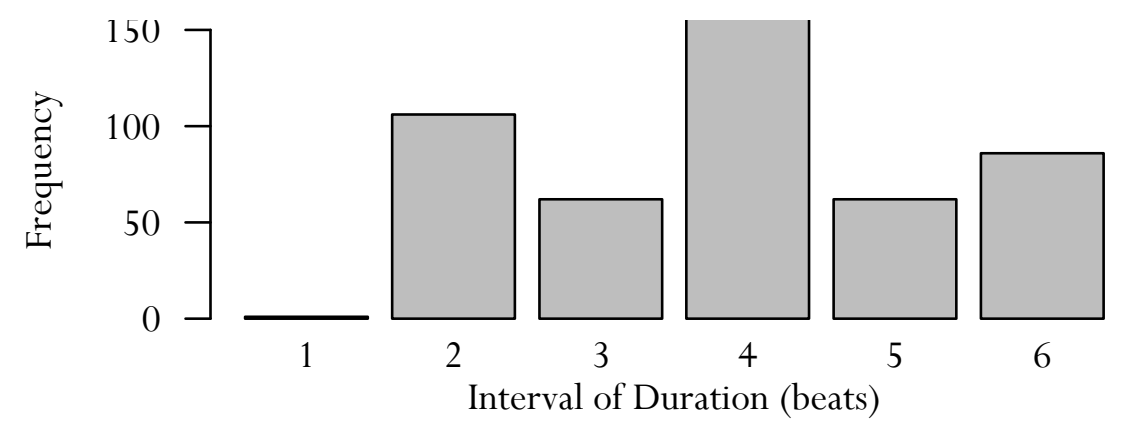

Fig. 11. Duration between beats that have an accent on the beat and one just before the start of the next beat. Other such beats may intervene. Note that a duration of one beat is impossible since the accentfinding algorithm does not allow accents on consecutive sixteenth notes.

\section{TRIPLE-METER TRACES IN VERSES OF “MAINSTREAM”}

With an understanding of how features of flow-phrase ending, rhyme projection, and rhythmic patterning - typically support rap's duple meter, we are prepared to examine the verses of "Mainstream" to seek the trace of the beat's triple meter. Appendix 2 transcribes the second verse, performed by André 3000 . Fig. 12 reprints the transcription, omitting the lyrics and only plotting the onsets of syllables that are the final accent of a rhyme instance or end a line or phrase. The upper row of plots assumes a three-beat measure; the lower row assumes a four-beat measure. The lower row of plots is much more patterned than the upper row. Every measure has a rhyme instance on or near the fourth beat and phrases and lines begin there as well.[16] Little of this structuring, however, is evident in the upper row of plots.

Indeed, there are few suggestions of triple meter in the material of André 3000's verse. Three beats separate only four pairs of rhyme instances out of a total of nearly forty pairs. These include divin'/Ivan in m. 1, Gretchen/rushin' between mm. 1 and 2, gotta/follow in m. 9, and down/down in m. 17 . All of these except Gretchen/rushin' (which some listeners might not hear as a rhyme anyway) mark the beginning of a four-measure group. In that sense, André 3000 not only employs very few three-beat rhymes, but those that he does use support the duple hypermeter.[17] Similarly, only a single line is three beats long: that of most of m. 7, so I'm gonna sing just like them. Although the rhythmic pattern discussed earlier is not especially common in André's verse, it does appear on the third beats of mm. 9-12 with the lyrics be that I fol-[low], down and then swal-[low], that's not my job, and know who you are. There, the pattern is always separated by four beats.

Given the importance André 3000 seems to attach to the metric ambiguity of "Mainstream," it may be surprising that he does so little to reflect this ambiguity in his rapping. But these expressive choices in rapping need not detract from the importance of the song's metric ambiguity. ATLiens marks Outkast's first production credit; André 3000 as an individual would not receive a production credit until the release of The Love Below in 2003. Perhaps we should understand the thoroughly duple nature of his emceeing in the verse as a way of letting the triple-meter aspect of the beat shine through without competition from the rapping.

T-Mo Goodie, on other hand, aligns many aspects of his verse with the triple-meter of the guitar in the beat (see a full transcription in Appendix 3). As I've learned the verse well enough to rap along with it, I find it increasingly difficult to feel the duple meter without hearing the accompanying tracks. This difficulty begins with the first word. There are six beats between T-Mo's entrance and the re-entrance of the drums. If you start by counting in three, the drums begin on a downbeat. If you starting counting in four, the drums begin on beat three, and this probably necessitates a readjustment. In one of the early rhymes in the verse, visions from me at twenty three making it free in my community, the durations between 
rhymes are a beat and a half or a beat a three quarters. While this duration bisects three beats, it bears no simple relation to four beats. The use of a beat and a half as an inter-rhyme duration also means that three beats separate every other rhyme instance. Another set of rhymes later in the verse, adapt and overcome, oh hum hum, go get my gun, load up for fun, reprises the beat-and-a-half inter-rhyme duration and the attendant three-beat rhyme projections.
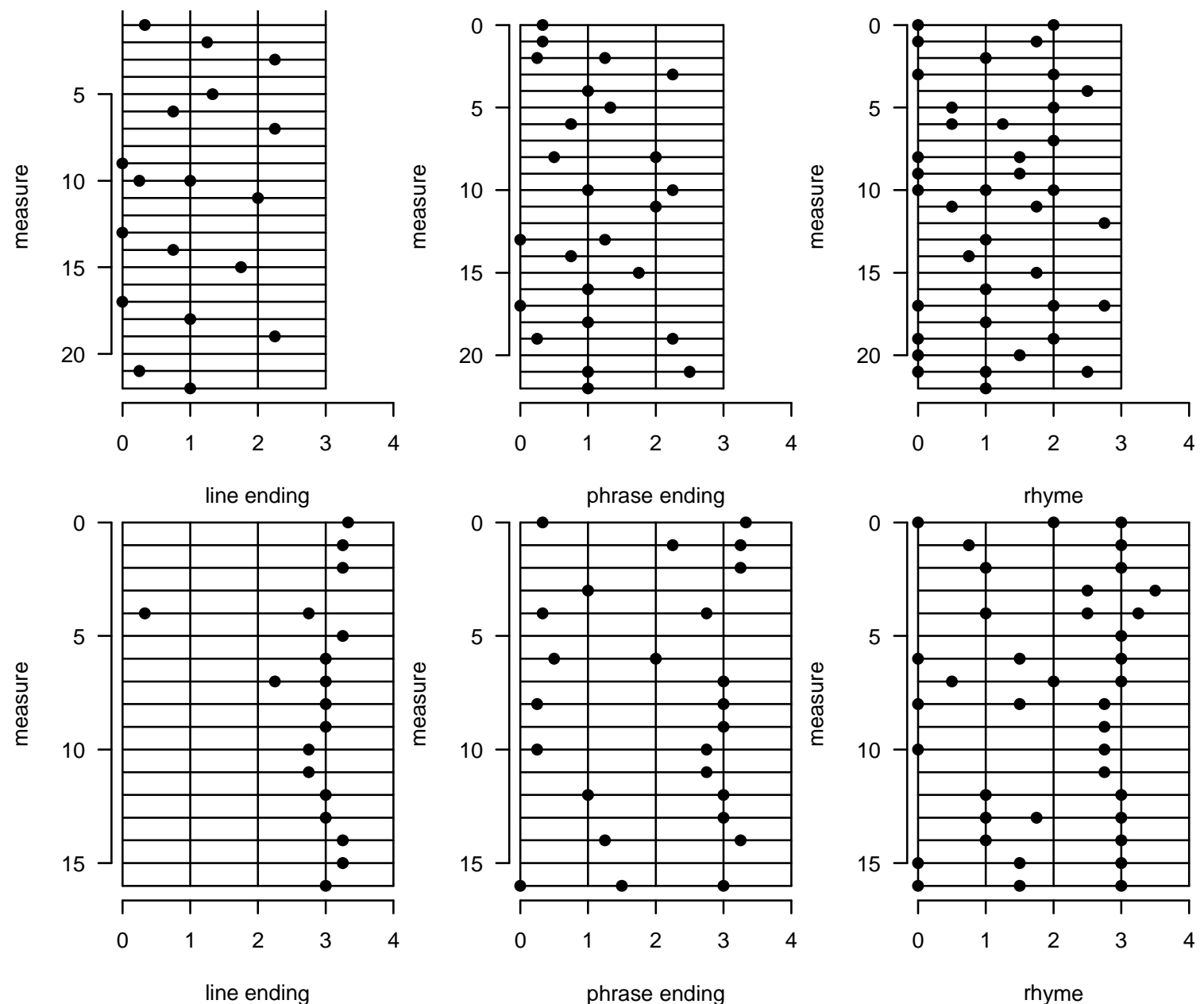

line ending

phrase ending

rhyme

Fig. 12. Alignment of line ending, phrase ending, and rhyme in André 3000's verse of “Mainstream,” with measure understood as three beats (above) and four beats (below).

Indeed, the placement of rhyme throughout the verse does much to support a three-beat metric hearing. Fig. 13 shows a similar set of plots to Fig. 12. Beginning in the fourth three-beat measure, and this is the word three in At twenty three, there is a rhyming syllable within half a beat of the third beat of every three-beat measure from measures 4-14. Beginning in measure 11, with the word frown, a rhyming syllable is heard on or near beat one of the three-beat measures for 8 measures ending in $\mathrm{m}$. 19.[18]

Yet T-Mo also shapes aspects of his flow to support the four-beat meter. He has several lines that are four beats in duration, lines like Words of a change I don't feel but I see (m. 3) and I got my boots I kick it until I get with (m. 7). And the most syllable-packed lines in the verse can be heard as anacruses or pickups plus a complete four-beat measure. These lines include I know its through them plenty figures, cocaine dealers walking the wrong side (m. 12), the fact the only way a nigga can survive the game (m. 19), and We kill each other just lost another brother fast living will get you took (m. 22). But while segmentation in many cases supports a four-beat measure, the four-beat plots of breath and line segmentation in Fig. 13 are not nearly as structured as those in André 3000's verse. The rhythmic pattern identified earlier is far more common in T-Mo's verse, occurring sixteen times. These generally recur in ways that support the duple 
meter. In mm. 7-9 the second beat of each measure contains the pattern (boots I kick, [a]-dapt and o[vercome], and gun load up); the pattern also recurs on the third beat of the measure four out of five measures in a row from mm. 18-22 (i.e., can you blame, [sur]-vive the game, dealing fa-[tal], and other just lost).
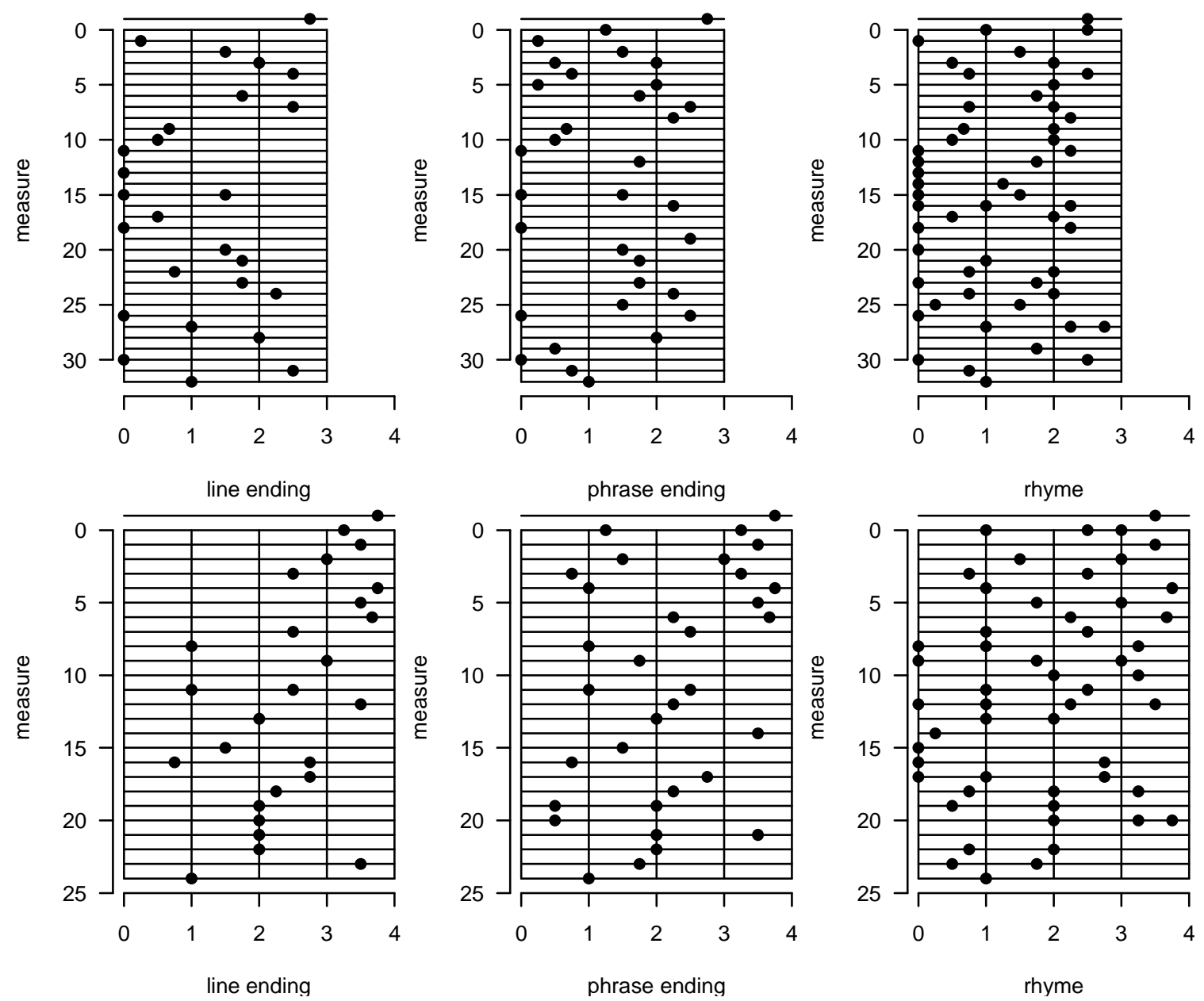

Fig. 13. Alignment of line ending, phrase ending, and rhyme in T-Mo Goodie's verse of "Mainstream," with measure understood as three beats (above) and four beats (below).

Anecdotally, then, it would seem that T-Mo, at least in some respects, has written a flow with triple-meter resonances. The corpus construction described above can support this assertion by documenting that the triple-meter features of T-Mo's flow are atypical, both within the genre as a whole and within T-Mo's output. Fig. 14 plots the rhyme projections of five different collections of verses: the seventy-five verses of the genre as a whole, ten verses of T-Mo Goodie, twenty-two verses of André 3000, and the first two verses of "Mainstream." Comparing the use of three- and four-beat inter-rhyme durations among the groups of verses, the example suggests that T-Mo employs three-beat rhymes slightly more than the average emcee and avoids four-beat rhymes compared to his peers. Comparing the relative prevalence of three- and four-beat rhymes, the example shows that four-beat rhymes are nearly four times more prevalent than three-beat rhymes in the genre and one-and-a-half times more prevalent in T-Mo's output, but equally distributed in T-Mo’s “Mainstream” verse. 


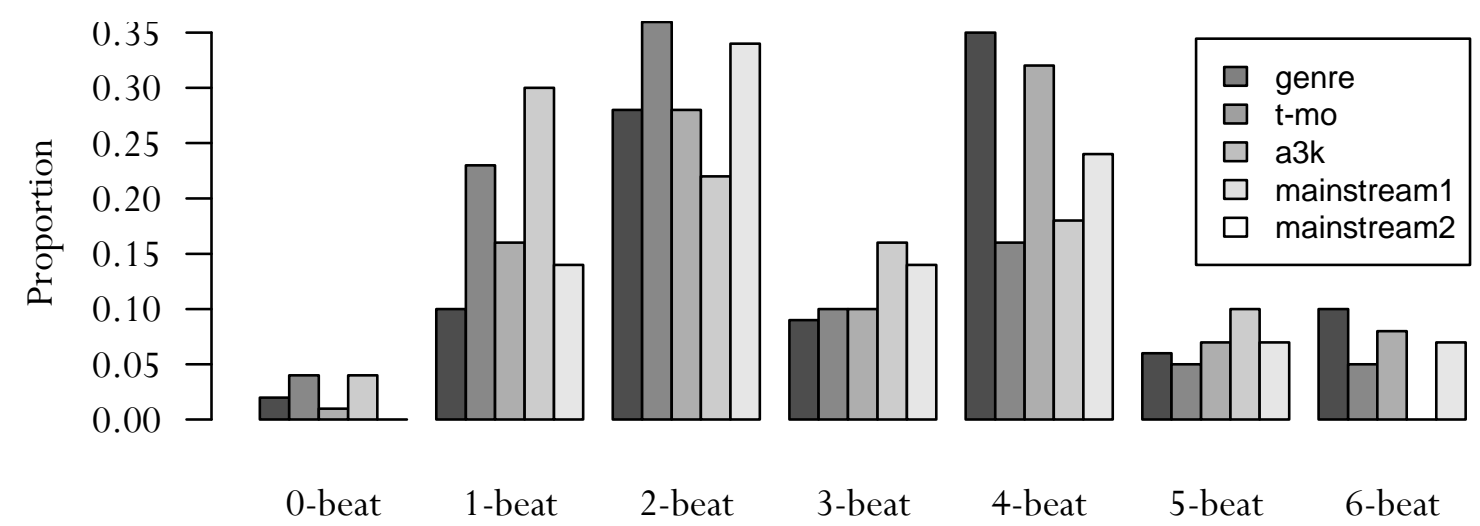

Fig. 14. Rhyme projection in the seventy-five verse corpus, the ten-verse T-Mo corpus, the twenty-two verse André 3000 corpus, T-Mo’s “Mainstream” verse (Verse 1), and André 3000’s “Mainstream” verse (Verse 3)

The column-like features of Fig. 13 and the distribution of rhyme durations in Fig. 14 are consistent with the idea that T-Mo prioritizes the triple-meter aspects of the "Mainstream" beat. But the material of his verse does far less to support a triple meter than the material of Bubba Sparxxx's "Deliverance" does to support a duple meter. I presume T-Mo could have crafted a verse in which phrase length and rhythmic patterning more fully supported the triple meter affordances of the beat, had he desired to do so. But perhaps the limited support of the triple meter is appropriate. The "Mainstream" beat is not a triple-meter beat — and to my knowledge, there are no unambiguously triple-metered beats in rap, although I'd like to be made aware of any that exist. What is remarkable about "Mainstream" is that aspects of it point towards triple meter. When I listen to this beat, I'm always aware that the guitar is in three, but of course I have a hard time suppressing the dupleness of the drums, especially since the drums are such a useful guide to understanding rap's meter in all other cases. It strikes me that T-Mo mirrors this experience of metric conflict by organizing the phonetic similarities of rhyme around the implicit triple meter while at the same time structuring the segmentation of the verse more often in alignment with the duple meter.

In this article I hope to have demonstrated the resonances between T-Mo's flow and the triplemeter aspects of "Mainstream." Further, I hope to have shown that corpus methods can supplement close readings of individual tracks and pieces as well as identify broad tendencies in a repertoire. Adopting these computational methods of analysis may daunt some scholars. Building a representation of the culturally relevant parameters of musical material is difficult, as is determining and encoding a representative sampling of a repertoire. The challenge for popular music is even greater, since so many existing musical codes address Western classical music.

But the payoff of adopting these methods should be enticing. The questions I address herewhether the metric ambiguity of "Mainstream" is evident in the material of the rapped verses-are often neglected by scholars in the humanities for fear that the answers can only be speculative, and that such speculations have often in the past been made with too little awareness of the particularities of a genre of music and those who make it. But corpus methods enable us to proffer speculative close readings that are rooted in broad observations of the repertoire. I hope that a more widespread adoption of corpus methodsguided by the ideas exposited in this special issue-will spur not only more clearly articulated portraits of genres, but also more grounded examinations of questions of expressive practice. 


\section{NOTES}

[1] The author invites correspondence addressed to Mitchell Ohriner, Lamont School of Music, 2344 E Iliff Ave, Denver, CO 80210, mohriner@gmail.com.

[2] Further discussion of compositional processes in rap music can be found in Adams (2009a), Williams (2009), Adams (2009b), Schloss (2014), and Adams (2015).

[3] The snare events are also called the backbeat and feature in many other genres of popular music.

[4] There are rap tracks that are not in $4 / 4$, many by artists who actively seek rhythmic complexity such as The Flobots, Busdriver, and Flying Lotus. But in a genre that has produced on the order of 100,000 tracks, there might be a couple dozen that are not in $4 / 4$.

[5] For a slice of a large and growing collection of analytically focused studies of popular music aimed at parameters other than harmony and form, see Bowman (1995), Bracket (2008), Burns (2005), Butler (2014), Butterfield (2006), Cusick (1999), and Griffiths (2003).

[6] In principle, one could align lyrics and audio through speech-to-text methods such as those used in the Penn Phonetics Forced Aligner program (Yuan \& Liberman 2008). This approach faces two hurdles. First, forced aligners will use machine phonetics dictionaries that omit many words encountered in rap lyrics (e.g., Carnegie Mellon Pronouncing Dictionary 1993). Second, the instrumental beat will hinder the performance of the aligner. If audio stream segmentation could extract the vocals, and if a large project to expand phonetics dictionaries to include words from African American Vernacular English were undertaken, then the automated transcription of rap verses might be possible. In the meantime, and "the meantime" might last a very long time, manual transcription is necessary.

[7] The Echo Nest API gives a start year for each of the 225 artists - the year of their first credit, not their birth year. I create three periods of rap music, ending in 1992 and 2002, that have the same number of artists. I also tag artists by their region as East Coast (including the DC area), Southern, Midwest, and West Coast. Both the population of artists and the sample in the corpus have equal distributions of the three chronological eras and are 45\% East Coast, 24\% Southern, 15\% West Coast, and 14\% Midwest.

[ 8 ] W Wikipedia contributors created a list of XXL Freshmen by year. See https://en.wikipedia.org/wiki/XXL_(magazine)\#XXL_Freshmen, accessed June 18, 2015

[9] This happens, for example, in the first verse of The Roots’s “The OtherSide” (Thompson et. al 2011).

[10] Hirjee and Brown (2010) present a system for automated rhyme detection. They achieve an error rate as low as $15 \%$. While there method is suitable for characterizing large collections of rap lyrics—and this, after all, is their aim—engaging in critical analysis requires a much lower error rate.

[11] I determine syllabic stress through the Carnegie Mellon University Pronouncing Dictionary (Lenzao \& Rudnicky 2007), along with an appendix to that dictionary that I authored to include common words of African American Vernacular English as well as rap neologisms.

[12] An uneasiness with consecutive accent is a rare note of congruence between approaches to accent in phonetics and music theory (Liberman \& Prince 1977, p. 255; Lerdahl \& Jackendoff 1983, p. 69).

[13] In the density function, the area under the curve equals one. Because lots of phrases and lines end near the fourth beat but not necessarily on the fourth beat, the density function shows the prominence of beat four in a way not as apparent through more common histograms.

[14] The window length of six beats is arbitrary. 
[15] The R programming language, like most computing environments, employs the "go to the even digit" protocol of the IEC 60559 standard when rounding values ending in .5. This rounds 0.5 to 0 (not 1!) and 1.5 and 2. Although this is probably not the route most people use in rounding, it is especially appropriate for rounding musical durations in rap music since duple durations are so prominent in the genre. The initial 0 in the rhyme projection vector is the rhyme of $\langle$ fine, dime $\rangle$, which was half a beat and was therefore rounded to 0. Since I am also interested in the triple-meter resonances in verses of "Mainstream," the "round to the nearest even" procedure would in some sense mistreat durations of 2.5. These should be rounded to 2 in duple meter and 3 in triple meters. However, there are no such durations in either verse I discuss in this article.

[16] I should note, however, that in the case of line segmentation, the definition of a line biases a four-beat meter.

[17] Adam Krims suggests the prominence of this device, noting that "it has become almost a stock figure to begin a new four-measure unit with either the ending of the previous syntactic unit (and/or rhyme complex), or a new, truncated one” (Krims, 2000, p. 50). If the beginning of a four-measure unit has the first instance of the new rhyme class and, as is typical, another instance will fall on the fourth beat, a threebeat inter-rhyme duration will result. See Rap Music, p. 50.

[18] Note that these events are not the same rhyme class. The resonance of the triple meter is probably weaker as one is getting to know the verse, since one initially doesn't know that the first instance of a rhyme class belongs to the class.

\section{REFERENCES}

Adams, K. (2009a). 'People's instinctive assumptions and the paths of narrative': A response to Justin Williams. Music Theory Online 15(2), accessed June 18, 2015. Retrieved from http://www.mtosmt.org/issues/mto.09.15.2/mto.09.15.2.adams.html

Adams, K. (2009b). On the metrical techniques of flow in rap music. Music Theory Online 15(5), accessed June 18, 2015. Retrieved from http://www.mtosmt.org/issues/mto.09.15.5/mto.09.15.5.adams.html

Adams, K. (2015). The musical analysis of hip-hop. In J. Williams (Ed.), The Cambridge Companion to Hip-Hop (pp. 118-134). New York: Cambridge University Press. https://doi.org/10.1017/CCO9781139775298.012

Biber, D. (1990). Methodological issues regarding corpus-based analyses of linguistic variation. Literary and Linguistic Computing 5, 257-69. https://doi.org/10.1093/llc/5.4.257

Bowman, R. (1995). The Stax sound: A musicological analysis. Popular Music 14(3), 285-320. https://doi.org/10.1017/S0261143000007753

Brackett, J. (2008). Examining rhythmic and metric practices in Led Zeppelin’s musical style. Popular Music 27(1), 53-76. https://doi.org/10.1017/S0261143008001487

Bradley, A. \& DuBois, A. (Eds.). (2010). The Anthology of Rap. New Haven: Yale University Press.

Brogan, T. (1993). Rhyme. In The New Princeton Encyclopedia of Poetry and Poetics (pp. 1052-1064). Princeton, NJ: Princeton University Press.

Burgoyne, J., Wild, J., \& Fujinaga, I. (2013). Compositional data analysis of harmonic structures in popular songs. In J. Yust, J. Wild, \& J. Burgoyne (Eds.), Mathematics and Computation in Music, pp. 52-63. Lecture Notes in Computer Science 7937. https://doi.org/10.1007/978-3-642-39357-0_4 
Burns, L. (2005). Feeling the style: Vocal gesture and musical expression in Billie Holiday, Bessie Smith, and Louis Armstrong. Music Theory Online 11(3), accessed June 18, 2015. Retrieved from http://mto.societymusictheory.org/issues/mto.05.11.3/mto.05.11.3.burns.html

Butler, M. (2014). Playing with Something that Runs. New York: Oxford University Press. https://doi.org/10.1093/acprof:oso/9780195393613.001.0001

Butterfield, M. (2006). The power of anacrusis: Engendered feeling in groove-based musics. Music Theory Online 12(4), accessed June 18, 2015. Retrieved from http://mto.societymusictheory.org/issues/mto.06.12.4/mto.06.12.4.butterfield.html

Caldwell, D. (2010). Making metre mean: Identity and affiliation in the rap music of Kanye West. In M. Bednarek \& J. Martin (Eds.), New Discourse on Language: Functional Perspectives on Multimodality, Identity, and Affiliation (pp. 59-79). New York: Bloomsbury Publishing.

Covach, J. (1999). Popular music, unpopular musicology. In N. Cook \& M. Everist (Eds.), Rethinking Music (pp. 452-70). New York: Oxford University Press.

Cusick, S. (1999). On musical performances of gender and sex. In E. Barkin \& L. Hamessley (Eds.), Audible Traces: Gender, Identity, and Music (pp. 25-48). Zürich: Carciofoli Verlagshaus.

Davies, M. (2008) The Corpus of Contemporary American English: 450 million words, 1990-present. Accessed June 18, 2015. Retrieved from http://corpus.byu.edu/coca/

De Clercq, T. \& Temperley, D. (2011). A corpus analysis of rock harmony. Popular Music 30(1), 47-70. https://doi.org/10.1017/S026114301000067X

Douglas, J. (2003). Deliverance. On Bubba Sparxxx: Deliverance, Interscope Records B0001147-02.

Drake, D., Martin, A., Baker, E. \& Insanul, A. (2012). The fifty most slept-on rappers of all time. Complex.com, November 16, 2012, accessed June 18, 2015. Retrieved from http://www.complex.com/music/2012/11/the-50-most-slept-on-rappers-of-all-time/

Edwards, P. (2009). How to Rap. Chicago: Chicago Review Press.

Frith, S. (1987). Towards an aesthetic of popular music. In R. Leppert \& S. McClary (Eds.), Music and Society: The Politics of Composition, Performance, and Reception (pp. 133-150). Cambridge: Cambridge University Press.

Gale, A. (2011). Fifty most influential rappers. B.E.T.com, September 23, 2011, accessed June 18, 2015. Retrieved from http://www.bet.com/music/photos/2011/09/50-most-influential-rappers.html. No longer available.

Griffiths, D. (2003). From lyric to anti-lyric: Analyzing the words in pop song. In A. Moore (Ed.), Analyzing Popular Music (pp. 39-59). Cambridge: Cambridge University Press. https://doi.org/10.1017/CBO9780511482014.003

Hayes, B. (1995). Metrical Stress Theory: Principles and Case Studies. Chicago, IL: University of Chicago Press.

Hirjee, H. \& Brown, D. (2010). Using automated rhyme detection to characterize rhyming style in rap music. Empirical Musicology Review 5(4), 121-145. 
Ide, N. \& Macleod, C. (2001). The American National Corpus: A standardized resource of American English. Proceedings of Corpus Linguistics 2001, Lancaster UK.

Johnson, I. (2015). Hip hop dance. In J. Williams (Ed.), The Cambridge Companion to Hip-Hop, pp. 2231. New York: Cambridge University Press. https://doi.org/10.1017/CCO9781139775298.004

Kautny, O. (2015). Lyrics and flow in rap music. In J. Williams (Ed.), The Cambridge Companion to HipHop (pp. 101-117). New York: Cambridge University Press. https://doi.org/10.1017/CCO9781139775298.011

Kreviazuk, C., Lamar, K., Rock, J. \& Sounwave. (2014). Pay for it. Non-album single.

Krebs, H. (1999). Fantasy Pieces: Metrical Dissonance in the Music of Robert Schumann. New York: Oxford University Press. https://doi.org/10.1093/acprof:oso/9780195116236.001.0001

Krims, A. (2000). Rap Music and the Poetics of Identity. New York: Cambridge University Press.

Ladefoged, P. \& Johnson, K. (2011). A Course in Phonetics, Sixth Edition. Boston, MA: Wadswordth.

Lamere, L. Hottt or nottt? Music Machinery (blog), December 9, 2009, accessed June 18, 2015. Retrieved from http://musicmachinery.com/2009/12/09/a-rising-star-or/

Lerdahl, F. \& Jackendoff, R. (1983). A Generative Theory of Tonal Music. Cambridge, MA: MIT Press.

Lenzao, K. \& Rudnicky, A. (2007). The Carnegie Mellon University Pronouncing Dictionary, Version 0.7a [2007], accessed June 18, 2015. Retrieved from http://www.speech.cs.cmu.edu/ cgi-bin/cmudict

Liberman, M. \& Prince, A. (1977). On stress and linguistic rhythm. Linguistic Inquiry 8(2), 249-336.

McClary, S \& Walser, R. (1990 [1988]). Start making sense!: Musicology wrestles with rock. In S. Frith \& A. Goodwin (Eds.), On Record: Rock, Pop, and the Written Word (pp. 277-92). New York: Pantheon Books.

Meyer, L. (1973). On the nature and limits of critical analysis. In Explaining Music: Essays and Explorations, pp. 3-25. Berkeley, CA: University of California Press.

Middleton, R. (1990). Studying Popular Music. New York: McGraw-Hill Education.

Miyakawa, F. (2005). Five Percenter Rap: God Hop’s Music, Message, and Black Muslim Mission. Bloomington, IN: Indiana University Press.

Muhammad, A. \& Kelley, F. (2014). André 3000: You can do anything from Atlanta. Microphone Check (podcast). September 26, 2014, accessed June 18, 2015. Retrieved from http://www.npr.org/sections/microphonecheck/2014/09/26/351559126/andre-3000-you-can-do-anythingfrom-atlanta

Müller, M. (2007). Pitch- and chroma-based audio features. In M. Müller (Ed.), Information Retrieval for Music and Motion, pp. 51-67. New York: Springer Science \& Business Media. https://doi.org/10.1007/978-3-540-74048-3_3

No author. (2016). Spotify Echo Nest API, accessed January 3, 2017. Retrieved from https://developer.spotify.com/spotify-echo-nest-api/. 
Patel, A. (2008). Music, Language, and the Brain. New York: Oxford University Press.

Quinn, I. \& White, C. (2015). Harmonic function in popular music. Paper presented at the Music Theory Society for the Mid-Atlantic Annual Meeting, Princeton University, Princeton, NJ. 15 March, 2015.

Ross, E. (2013). The Fifty Best Selling Rap Albums of All Time, Complex.com, May 18, 2013, accessed June 18, 2015. Retrieved from http://www.complex.com/music/2013/05/the-50-best-selling-rap-albums/

Sarig, R. (2007). Third Coast: OutKast, Timbaland, and How Hip-Hop Became a Southern Thing. Da Capo Press.

Selfridge-Field, E. (1997). Beyond MIDI: The Handbook of Musical Codes. Cambridge, MA: MIT Press.

Schloss, J. (2014). Making Beats: The Art of Sample-Based Hip-Hop. Middletown, CT: Wesleyan University Press.

Shepherd, J. (1982). A theoretical model for the sociomusicological analysis of popular musics. Popular Music 2, 145-77. https://doi.org/10.1017/S0261143000001276

Shepherd, J. (1991). Music as Social Text. New York: Polity Press.

Temperley, D. (2011). The cadential IV in rock.” Music Theory Online 17(1), accessed June 18, 2015. Retrieved from http://www.mtosmt.org/issues/mto.11.17.1/mto.11.17.1.temperley.html.

Thompson, A., Gray, J., Mateen, K., Douglas, K., Hubbard, L., Smart, M., \& Trotter, T. (2006). Game Theory. On The Roots: Game Theory. Def Jam Recordings 00602517001268.

Thompson, A., Poser, J., Jenkins, K., Spearman, G. \& Trotter, T. (2011). The otherside. Track six on Undun. Def Jam Recordings B0016282-02.

Various authors. (2012). Top fifty lyrical leaders. The Source, June 26, 2012, 66-75.

Williams, J. (2009). Beats and flows: A response to Kyle Adams. Music Theory Online 15(2), accessed June 18, 2015. Retrieved from http://www.mtosmt.org/issues/mto.09.15.2/mto.09.15.2.williams.html

Wood, B. (1999). Understanding rap as rhetorical folk-poetry. Mosaic, 32(4).

Woods, A. (2009). Rap vocality and the construction of identity. Unpublished Ph.D. dissertation, University of Michigan.

Yasin, J. (1997). In Yo Face! Rappin’ Beats Comin' at You: A Study of How Language Is Mapped onto Musical Beats in Rap Music. Unpublished doctoral dissertation, Columbia University, US. ProQuest, DA9734099.

Yuan, J. \& Liberman, M. (2008). Speaker identification on the SCOTUS corpus. Proceedings of Acoustics '08, accessed June 18, 2015. Retrieved from http://www.ling.upenn.edu/ jiahong/publications/c09.pdf. https://doi.org/10.1121/1.2935783 


\section{APPENDIX 1: THE ACCENT-LABELING ALGORITHM}

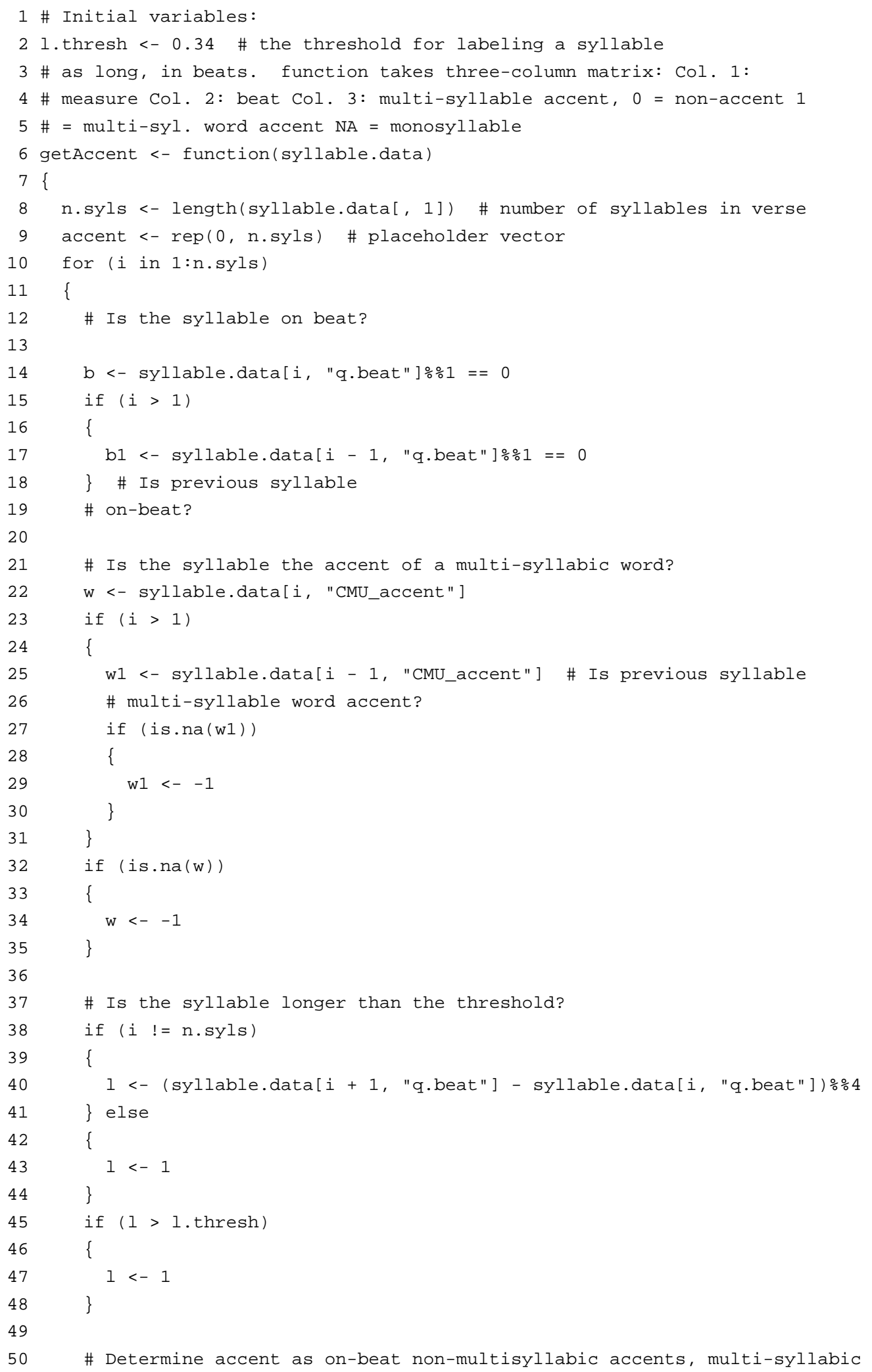




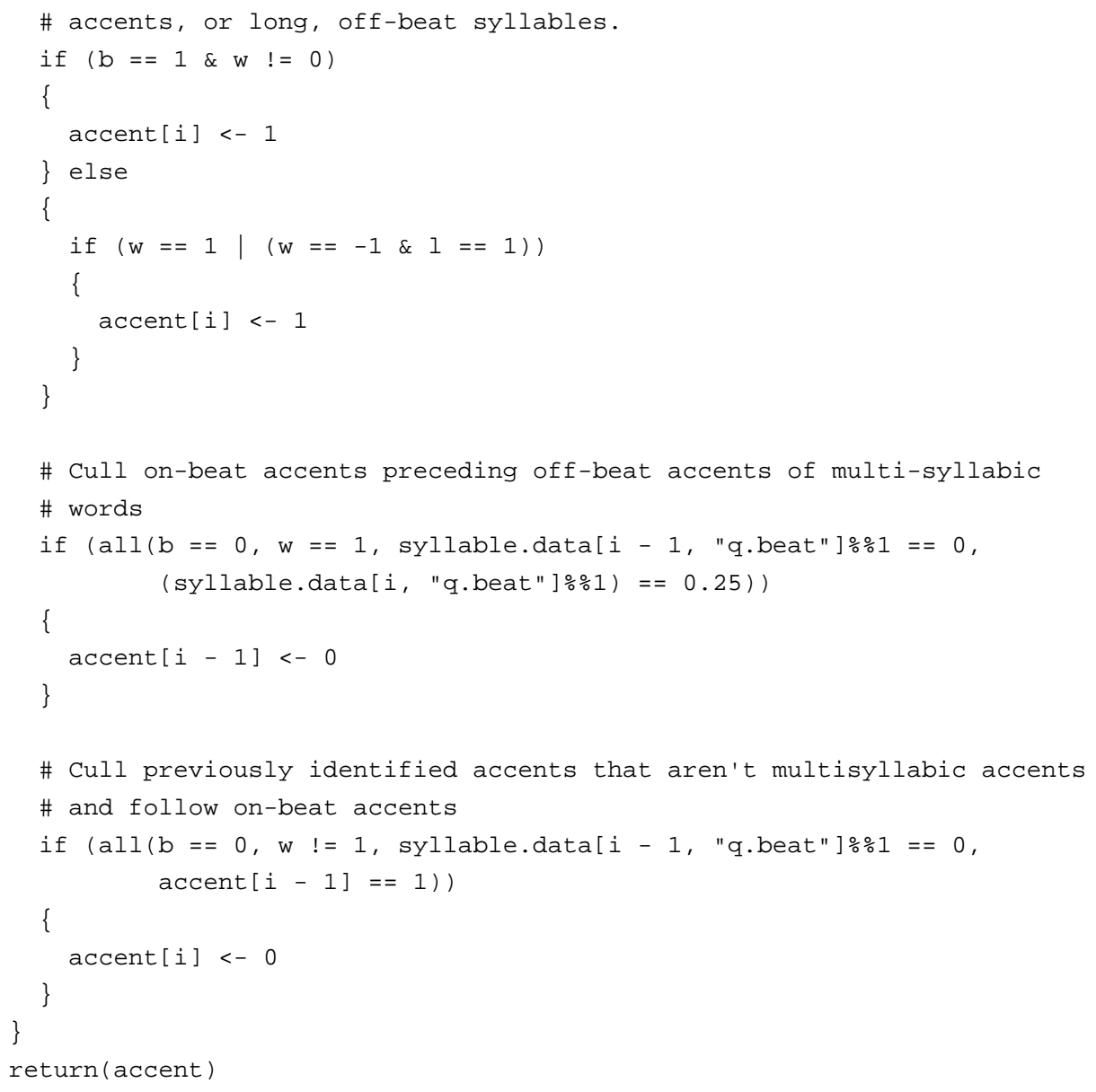




\section{APPENDIX 2: ANDRÉ 3000’S “MAINSTREAM” VERSE}

0
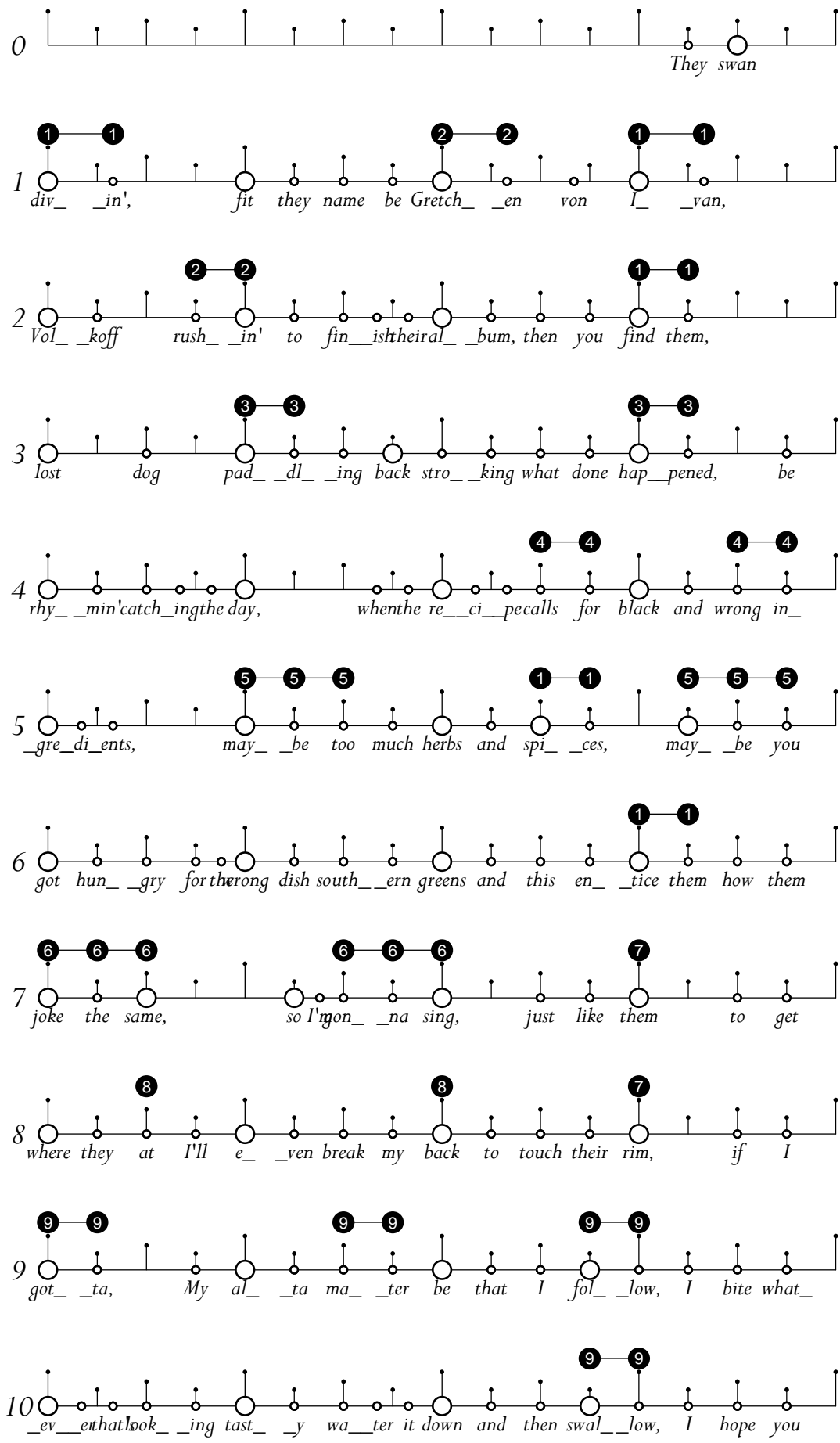


\section{APPENDIX 2, CONTINUED}
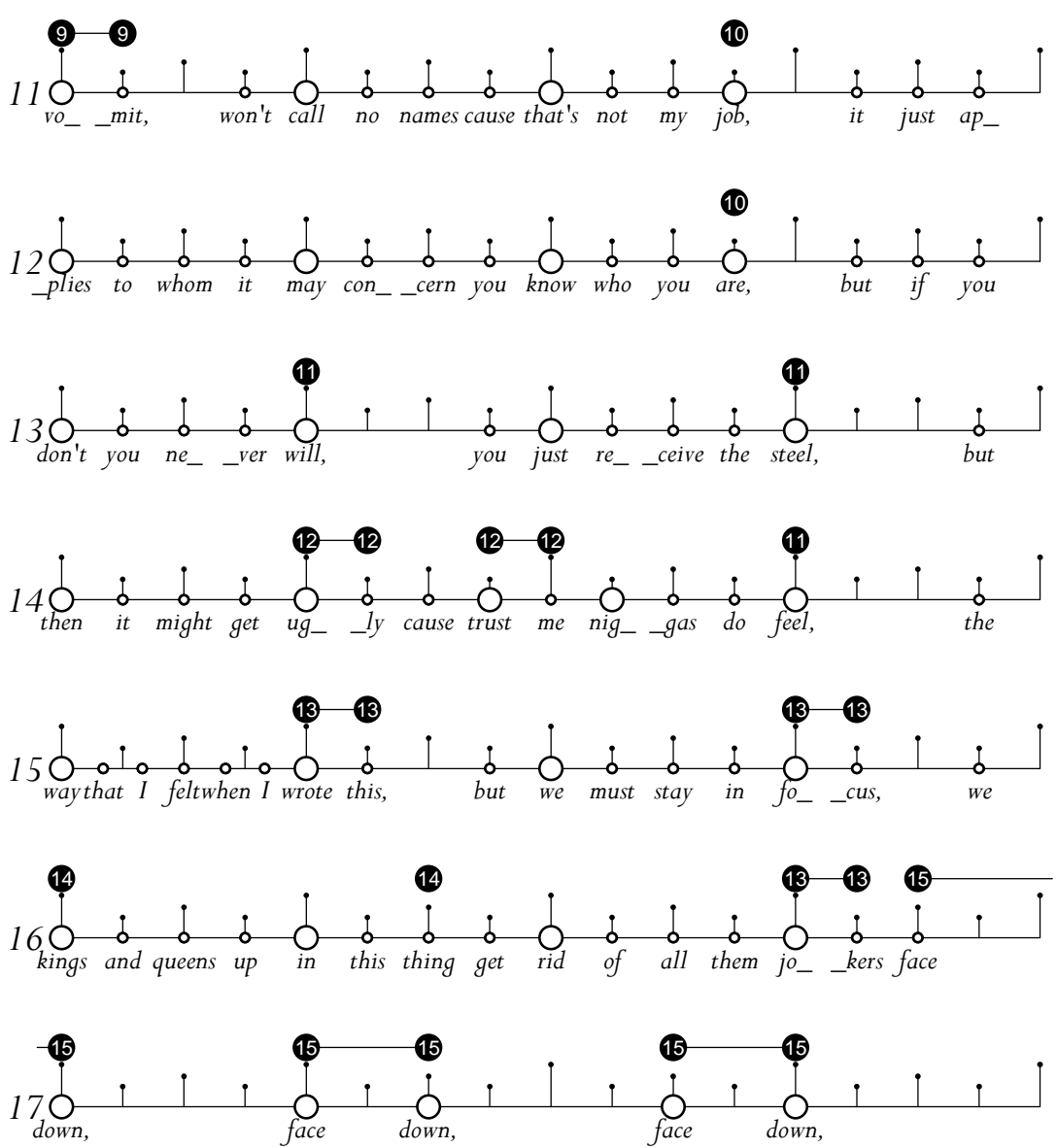


\section{APPENDIX 3: T-MO GOODIE'S “MAINSTREAM” VERSE}
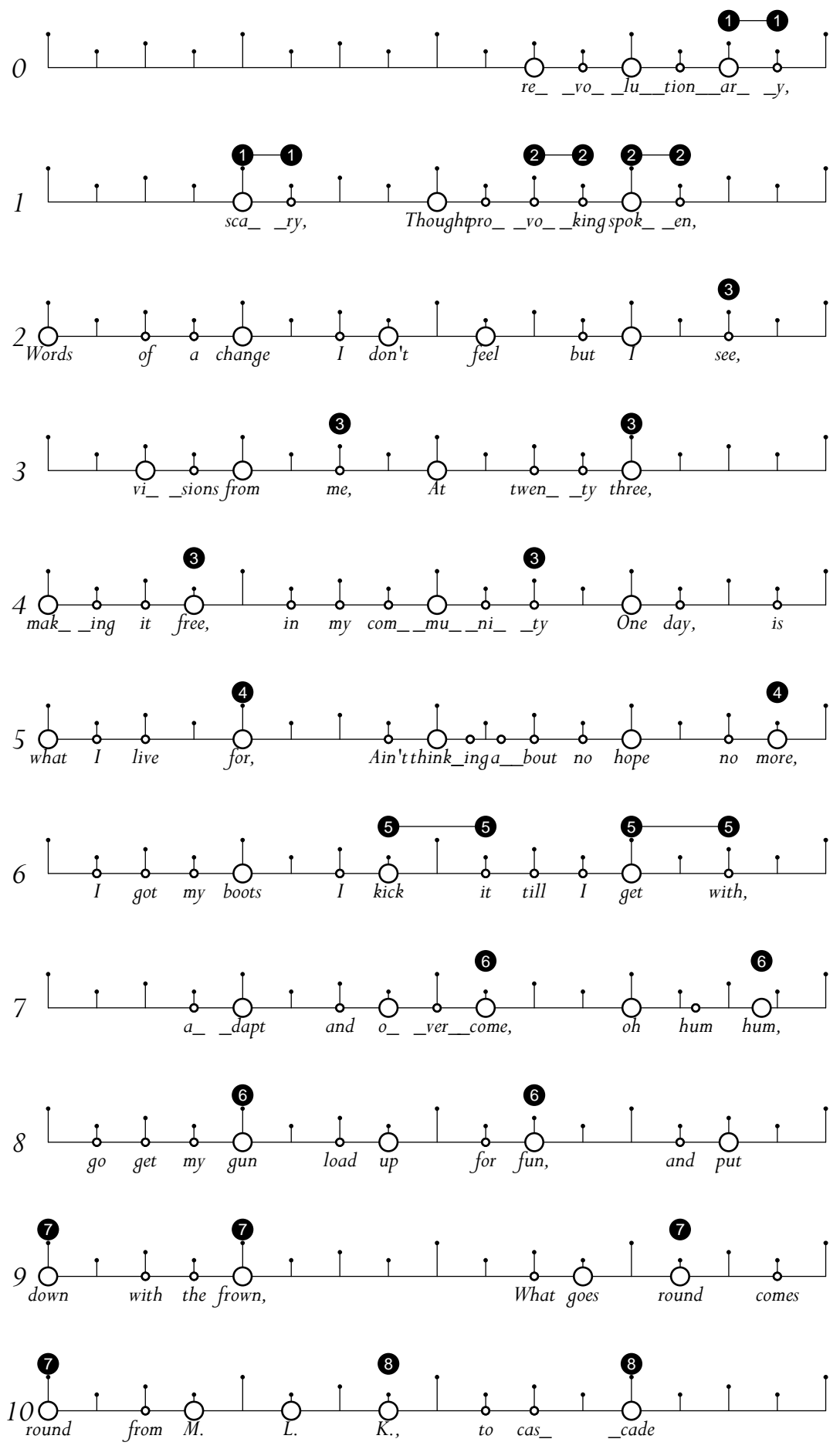


\section{APPENDIX 3, CONTINUED}
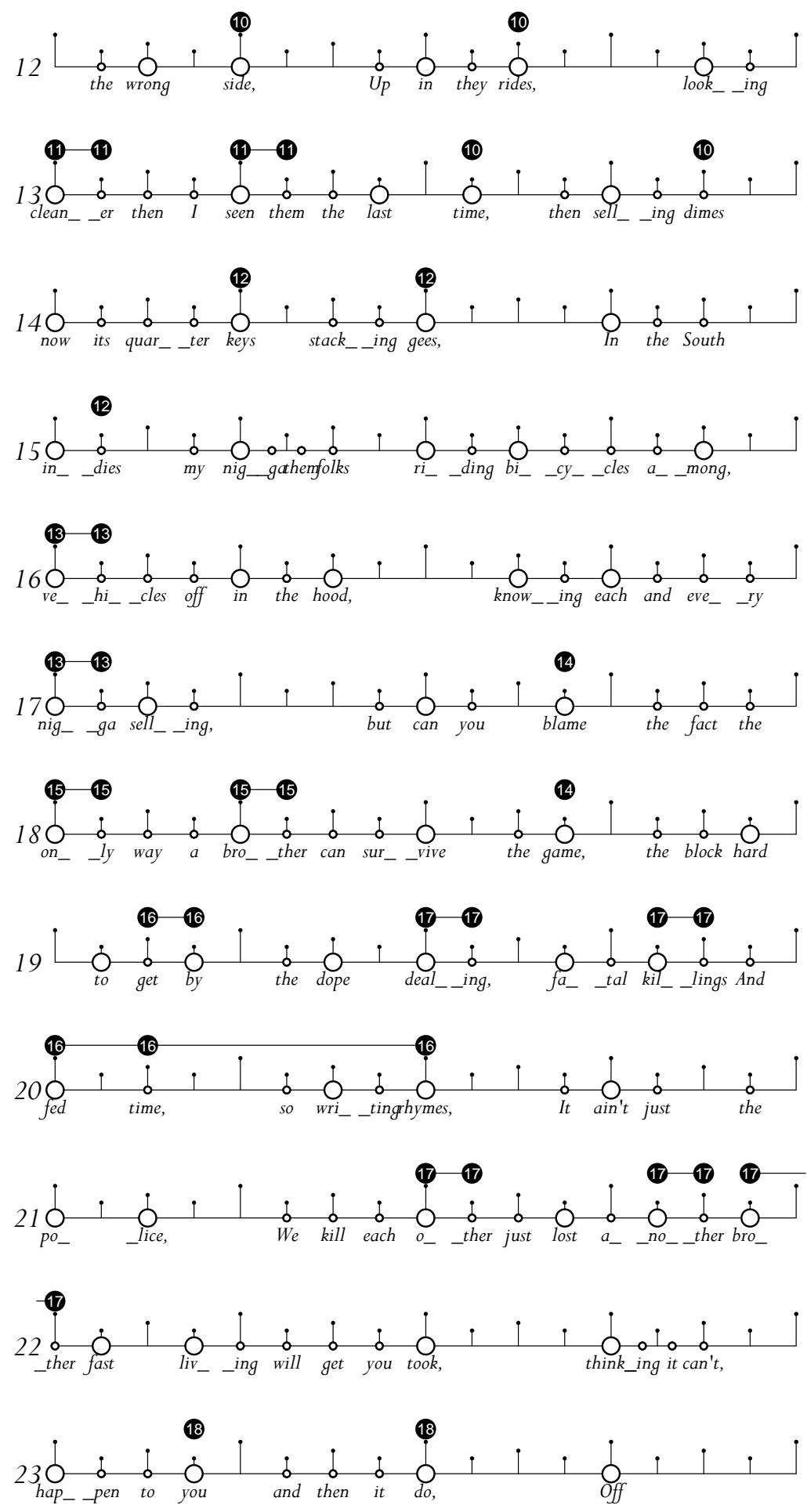


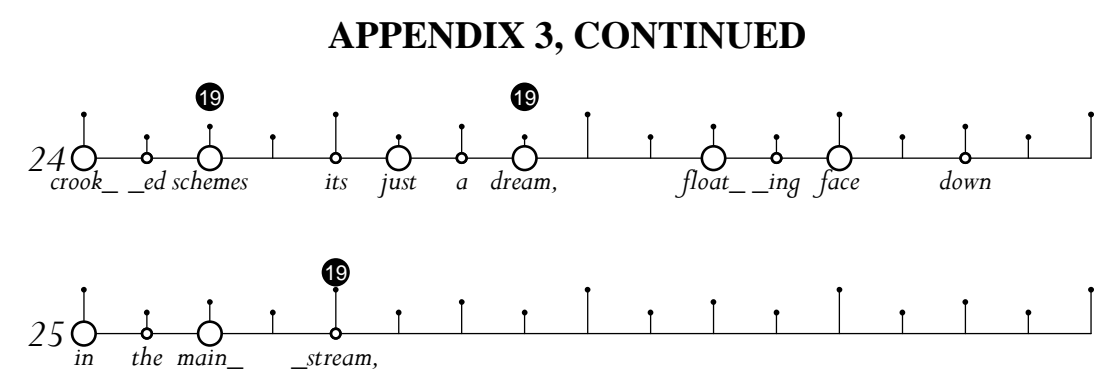

\section{APPENDIX 4: SONGS IN CORPORA}

Songs in seventy-five verse, genre-wide corpus:

50 Cent. (2005). "Candy Shop.” The Massacre.

Action Bronson. (2015). "Easy Rider.” Mr. Wonderful.

August Alsina. (2014). "No Love.” Testimony.

Big Boi. (2010). "Shutterbugg.” Sir Lucious Left Foot: The Son of Chico Dusty.

Big Daddy Kane. (1988). “Ain’t No Half-Steppin’.” Long Live the Kane.

Big K.R.I.T.. (2014). "Cadillactica.” Cadillactica.

Black Rob. (2000). "Whoa.” Life Story.

Blu. (2011). "Amnesia." Her Favorite Colo(u)r.

Bone Thugs-n-Harmony. (1997). "Thug Love.” Art of War.

Brother Ali. (2004). "Self Taught." Champion EP.

Bubba Sparxxx. (2003). "Deliverance.” Deliverance.

Canibus. (1998). "Second-Round K.O.” Can-I-Bus.

Cashis. (2012). “Water Whippin'.” The Art of Dying.

Casual. (1994). "That's How It Is.” Fear Itself.

Danny Brown. (2014). “25 Bucks (featuring Purity Ring).” Old.

De La Soul. (1989). "Me Myself and I." 3 Feet High and Rising.

Diggy Simmons. (2012). "Do It Like You.” Unexpected Arrival.

Dizzy Wright. (2012). "Can’t Trust Em.” SmokeOut Conversations.

Dr. Dre. (1999). “The Next Episode.” 2001.

Esham. (1993). "Sunshine.” Sunshine.

Fabolous. (2013). "Ready.” Loso’s Way 2: Rise to Power.

Gang Starr. (1999). "Full Clip.” Full Clip: A Decade of Gang Starr.

Ghostface Killah. (2000). "Mighty Healthy." Supreme Clientele.

Gorilla Zoe. (2008). “Lost.” Don’t Feed Da Animals.

Grandmaster Flash. (1983). “The Message.” Grandmaster Flash \& The Furious Five.

Ice Cube. (1992). "It Was A Good Day.” The Predator.

Jadakiss. (2001). “We Gonna Make It.” Kiss tha Game Goodbye.

Jay Rock. (2014). "Pay for It.” Single.

Jay-Z. (2013). "Holy Grail.” Magna Carta Holy Grail.

Jean Grae. (2003). "My Crew.” The Bootleg of the Bootleg EP.

OJ da Juiceman. (2007). "Make Tha Trap.” The Otha Side of the Trap.

Kanye West. (2007). "Stronger.” Graduation.

Kilo Ali. (1997). "Baby, Baby .” Organized Bass.

Kirko Bangz. (2011). “Drank in My Cup.” Progression 2: A Young Texas Playa.

Kool Keith. (1997). “Sex Style.” Sex Style.

KRS-One. (1995). “MC’s Act Like They Don’t Know.” KRS-One. 
Kurtis Blow. (1980). “The Breaks.” Kurtis Blow.

Lil’ B. (2010). “Wonton Soup.” Blue Flame.

Lil' Boosie. (2006). "Set It Off.” Bad Azz.

Lil' Durk. (2013). "Dis Aint What U Want.” Signed to the Streets.

Lil' Kim. (2005). "Lighters Up.” The Naked Truth.

Lizzo. (2013). "Batches and Cookies.” Lizzobangers.

Logic. (2014). "Under Pressure.” Under Pressure.

Ludacris. (2010). "My Chick Bad.” Battle of the Sexes.

Lupe Fiasco. (2011). "The Show Goes On.” Lasers.

Mac Mall. (1993). "My Opinion.” Illegal Business.

Max B. (2008). "Sexy Love.” Million Dollar Baby 2.

Missy Elliott. (2001). "Get Ur Freak On.” Miss E ... So Addictive.

Nelly . (2002). "Dilemma." Nellyville.

No Malice. (2012). "June.” Hear Ye Him.

Peedi Crakk. (2003). “One for Peedi Crakk.” Single.

Phonte. (2011). "The Good Fight.” Charity Starts at Home.

Pill. (2011). "Pacman.” Self Made Vol.1.

P.M.D.. (1997). “It's the Pee '97.” Bu\$ine\$\$ is Bu\$ine\$\$.

Queen Latifah. (1993). “U.N.I.T.Y.” Black Reign.

Rick Ross. (2010). “Aston Martin Music (featuring Chrisette Michele and Drake).” Teflon Don.

Salt-N-Pepa. (1992). "Whatta Man.” Funky Divas.

Schoolboy Q. (2014). "Studio.” Oxymoron.

Slaughterhouse. (2014). "Y’all Ready Know." Shady XV.

Slick Rick. (1988). “Children’s Story.” The Great Adventures of Slick Rick.

Snoop Dogg. (2004). “Drop It Like It’s Hot.” $R$ \& G (Rhythm \& Gangsta).

Suga Free. (1996). "If U Stay Ready.” Street Gospel.

The Coup. (2012). "The Magic Clap.” Sorry to Bother You.

The Roots. (1996). "What They Do.” Illadelph Halflife.

The Treacherous Three. (1994). "Feel The New Heartbeat.” Old School Flava.

Three-Six Mafia. (2010). "Stay Fly.” Ten Toes Down.

Tim Dog. (1991). "Fuck Compton.” Penicillin on Wax.

UGK. (2001). “Pimpin’ Ain’t No Illusion.” Dirty Money.

Wale. (2011). "Ambition (featuring Meek Mill and Rick Ros).” Ambition.

Wise Intelligent. (1996). "Steady Slangin'.” Killin’ For Fun.

Wiz Khalifa. (2011). "Black and Yellow." Rolling Papers.

Wu-Tang Clan. (1993). “C.R.E.A.M.” Enter the Wu-Tang (36 Chambers).

Yelawolf. (2014). "Till It’s Gone.” Love Story.

YG. (2014). “Who Do You Love?” My Krazy Life.

Young Bleed. (1998). “The Day They Make Me the Boss.” My Balls and My Word.

Songs in the T-Mo Goodie corpus, from Goodie Mob albums unless otherwise noted:

From Soul Food, 1995: "Cell Therapy"

From Still Standing, 1998: “Greeny Green,” "Fly Away,” “Distant Wilderness,” “I Refuse

Limitation," "Inshullah"

From World Party, 1999: "Cutty Buddy,” "Get Rich to This,” “All As”

From Purple Ribbon All-Stars's Got Purp? Vol. 2, 2005: "Hold On”

Songs in the André 3000 corpus, exclusively from Outkast albums: 
From ATLiens, 1996: “Two Dope Boyz (In a Cadillac)," “ATLiens,” "Wheelz of Steel," "Jazzy Belle," "Elevators (Me \& You) [verses 1 and 4]," Ova Da Wudz," "Babylon [verses 1 and 2]," "Wailin," "Millennium," " $13^{\text {th }}$ Floor/Growing Old," and "E. T. (Extraterrestial)" From Aquemini, 1998: "Y’All Scared (featuring T-Mo, Big Gipp, and Khujo)" From Stankonia, 2000: "Humble Mumble, featuring Erykah Badu," "Gangsta Shit, featuring Slimm Calhoun, Blackowned C-Bone, and T-Mo," "Gasoline Dreams, featuring Khujo," "B.O.B. [Bombs Over Baghdad]," and "Xplosion featuring B-Real." 